\title{
Solubility of syngas components in water acetic acid and alcohol using new standard fugacity methodology
}

Torli, Mauro; Geer, Luydmila; Kontogeorgis, Georgios M.; Fosbøl, Philip L.

Published in:

Industrial and Engineering Chemistry Research

Link to article, DOI:

10.1021/acs.iecr.8b03954

Publication date:

2018

Document Version

Peer reviewed version

Link back to DTU Orbit

Citation (APA):

Torli, M., Geer, L., Kontogeorgis, G. M., \& FosbøI, P. L. (2018). Solubility of syngas components in water acetic acid and alcohol using new standard fugacity methodology. Industrial and Engineering Chemistry Research, 57, 16958-16977. https://doi.org/10.1021/acs.iecr.8b03954

\section{General rights}

Copyright and moral rights for the publications made accessible in the public portal are retained by the authors and/or other copyright owners and it is a condition of accessing publications that users recognise and abide by the legal requirements associated with these rights.

- Users may download and print one copy of any publication from the public portal for the purpose of private study or research.

- You may not further distribute the material or use it for any profit-making activity or commercial gain

- You may freely distribute the URL identifying the publication in the public portal 


\title{
Solubility of syngas components in water acetic acid
}

\author{
and alcohol using new standard fugacity
}

\section{methodology}

\author{
Mauro Torli, Luydmila Geer, Georgios M. Kontogeorgis, Philip L. Fosbøl* \\ Center for Energy Resources Engineering (CERE), Department of Chemical and Biochemical \\ Engineering, Technical University of Denmark, DK-2800 Lyngby, Denmark
}

Keywords: Vapor-liquid equilibria; gas solubility; Henry’s law constant; solubility in mixed solvents; UNIQUAC; ethanol; water; acetic acid; $\mathrm{CO}_{2} ; \mathrm{CO} ; \mathrm{CH}_{4} ; \mathrm{N}_{2} ; \mathrm{H}_{2}$

Abstract: The UNIQUAC model in combination with the Peng-Robinson and the HaydenO'Connell Virial equation of state was used for correlating vapor-liquid equilibrium for a gassolvent system containing: $\mathrm{CO}_{2}$-Water, $\mathrm{CO}_{2}$-Ethanol, $\mathrm{CO}_{2}$-Acetic acid, CO-Water, CO-Ethanol, CO-Acetic acid, $\mathrm{CH}_{4}$-Water, $\mathrm{CH}_{4}$-Ethanol, $\mathrm{CH}_{4}$-Acetic acid, $\mathrm{N}_{2}$-Water, $\mathrm{N}_{2}$-Ethanol, $\mathrm{N}_{2}$-Acetic acid, $\mathrm{H}_{2}$-Water, $\mathrm{H}_{2}$-Ethanol. Prausnitz and Shair correlation, for the fugacity of the hypothetical liquid solute at a pressure of $1 \mathrm{~atm}$, was implemented in the parametrization procedure as additional objective function so as to reduce the uncertainty on the constants of the model. The results show that the UNIQUAC equation, coupled with an appropriate equation of state to model the vapor phase non ideality, is able to represent the binaries in the range of temperatures and pressures considered in the study, i.e. from 0 to $310^{\circ} \mathrm{C}$, and from 1 to $400 \mathrm{bar}$, respectively. 
In addition to model parameter estimation, a new generic method to evaluate gas solubility in mixed solvents based on the thermodynamic relation of Henry's law constant with the activity coefficient at infinite dilution, has been derived. Provided the binary parameters of a generic excess Gibbs energy model, the gas solubility in the multicomponent system can be readily estimated. 


\section{Introduction}

There is in today's society an increasing focus towards production of greener fuels and chemicals which do not originate from fossil fuels. One way to accomplish this is by using synthesis gas (syngas) as a resource. Today, syngas is mainly produced from thermal gasification of coal and natural gas steam reforming. Uses of syngas include methanol synthesis, hydrogen production for ammonia and oil refineries, Fischer-Tropsch fuels, iron reduction and power generation. There is an increasing need to use more green resources for syngas formation. Therefore, syngas obtained from thermal gasification of biomass has grown substantially in the last decades ${ }^{1}$.

The focus of this work is on green syngas fermentation. It is one of several emerging technologies for the production of biofuels from renewable sources. In this process biomass is gasified to syngas ( $\mathrm{CO}$ and $\mathrm{H}_{2}$ ), which is then fermented by acetogenic bacteria to produce ethanol, acetic acid or other chemical commodities ${ }^{2}$.

The rate-limiting step of syngas fermentation is the gas-to-liquid mass transfer, and mass transfer limitations are expected to be even more severe than in the ordinary aerobic fermentation based on glucose. Indeed, $\mathrm{CO}$ and $\mathrm{H}_{2}$ solubilities are only $60 \%$ and $4 \%$ of $\mathrm{O}_{2}$, and more moles of gas must be transferred per carbon equivalent consumed. One way to improve the mass transfer is to increasing the mass transfer driving force. This is accomplished by raising the partial pressure of the syngas ${ }^{3}$. In order to estimate the equilibrium condition at high solute concentration, the Henry's law is not sufficient, especially above 5-10 bar and for molar fractions larger than $0.03^{4}$.

A widely studied example of a supercritical component in polar associating solvent is $\mathrm{CO}_{2^{-}}$

$\mathrm{H}_{2} \mathrm{O}$. Carroll and Mather (1992) ${ }^{5}$ provide a historical overview of this system. The simple 
Krichevsky-Kasarnovsky approach was found to be valid up to about 100 bar; the modified Krichevsky-Ilinskaya approach, where the un-symmetric activity coefficient is estimated using Margules equations ${ }^{6}$, made the modelling valid up to 1000 bar.

Another $\gamma-\varphi$ approach was applied by Duan and Sun (2003) ${ }^{7}$ to the more complex $\mathrm{CO}_{2}$ brine system up to 2000 bar. Pitzer equation ${ }^{8}$ was used for the non-ideal liquid behavior.

With the introduction of Huron-Vidal mixing rules $(1979){ }^{9}$, it became possible to combine the advantages of cubic equation of state (EoS) with activity coefficient models in order to have a framework valid both at very high pressures and for polar compounds that exhibit high deviations from ideality in the liquid phase. An application of this method to the system $\mathrm{CO}_{2}$ $\mathrm{H}_{2} \mathrm{O}$ can be found in the study of Pedersen et al. (2001) ${ }^{10}$.

Another approach to thermodynamic modelling of complex mixtures is the Cubic-Plus Association (CPA) equation of state, introduced by Kontogeorgis et al. (1996) ${ }^{11}$ to account for the effect of hydrogen-bonds and related phenomena. CPA is based on a cubic equation, usually the Soave-Redlich-Kwong (SRK) EoS, and the association term is taken from SAFT (Statistical Associating Fluid Theory ${ }^{12}$ ). The equation have been used to model $\mathrm{CO}_{2}-\mathrm{H}_{2} \mathrm{O}$ and/or ternaries systems containing the two components first in 2006 by Kontogeorgis et al. ${ }^{13}$ Austegard et al. ${ }^{14}$ and Perakis et al. ${ }^{15}$. By now several thermodynamic studies have been published on $\mathrm{CO}_{2}-\mathrm{H}_{2} \mathrm{O}$ and related systems. Many of these studies apply CPA for all phases, but some still use $\gamma-\varphi$ approach even at relative high pressure conditions, e.g. García et al. (2006) ${ }^{16}$, Spycher and Pruess (2010) ${ }^{17}$, Hou et al. (2013) ${ }^{18}$, Mao et al. (2013) ${ }^{19}$ and Venkatraman et al. (2014) ${ }^{20}$.

In this work we focus on the thermodynamic of 15 systems which may be of relevance for process simulation studies in connection with the biological synthesis of solvents, chemicals or the production of biofuels from syngas. A thermodynamic model is presented which describes 
the solubility of $\mathrm{CO}, \mathrm{H}_{2}, \mathrm{CO}_{2}, \mathrm{CH}_{4}$ and $\mathrm{N}_{2}$, i.e. the main component of biomass derived syngas, in combination with the three polar hydrogen bonding solvents: water, ethanol and acetic acid. The selected method is $\gamma-\varphi$ approach: UNIQUAC-Peng-Robinson (PR) for system containing water and ethanol, and UNIQUAC-Hayden-O'Connell Virial EoS for systems containing acetic acid. An explanation of the modelling, using a mix of PR and Hayden-O'Connell for the gas phase, is discussed in section 3.

The data regression has been performed with additional constraints on the supercritical component standard state fugacities and, on the same thermodynamic basis; a new approach for gas solubility in mixed solvents has been derived. This approach has been implemented in order

to avoid the derivation of ill-defined UNIQUAC parameters that are merely correlations and produce wrong property prediction of particularly $\gamma^{\infty}$. Indeed there is a need for future researches to address the fact that a consistent thermodynamic framework should be adopted whenever the $\gamma-\varphi$ approach is applied to gas solubility.

The gas solubility equilibria investigated in this study are of particular relevance to the syngas fermentation process, however they are also central to many other industrial applications, such as: ethanol and acetic acid fermentation, carbonation of alcoholic beverages and soft drinks, gas absorption, stripping columns, waste-water treatment, etc. ${ }^{21}$

\section{Theory of the applied thermodynamic modeling}

\subsection{The $\gamma-\varphi$ approach close to the critical conditions}

The $\gamma-\varphi$ approach has been used, and is still used, to successfully correlate solubility data also at high pressure. It is often stated that the concept cannot be used at high pressure due to various limitations and here we highlight some of the concerns in the existing activity coefficient models which are not present when using EoS’. 
Though there are some exceptions ${ }^{22}$, activity coefficient model are in general pressure independent expressions ${ }^{23}$ and they cannot account for the effect of this variable on the excess Gibbs energy $G^{E}$ of the system. This is equivalent to not considering the change in volume upon mixing, $V^{E} \cong 0$, as indicate in Eq. (1).

$d G^{E} \simeq-S^{E} d T+\sum_{i} \mu_{i}^{E} d n_{i} ; \quad V^{E} d P \simeq 0$

The contribution of the term $\int V^{E} d P$ to the excess Gibbs energy $G^{E}$ may become important at high pressure for systems with very large excess volumes. Nevertheless the practical limitations with the $\gamma-\varphi$ approach are due to the incorrect estimates on standard state liquid fugacities for components near critical conditions, rather than neglecting the pressure effect on $G^{E}$.

The standard state liquid fugacities at $T$ and $P$ are obtained from the saturation (vapor) pressure at $T$ applying two corrections: 1.A fugacity coefficient at saturated conditions, $\left.\varphi_{i}^{L}(T)\right|_{P_{i}^{s a t}}$ usually calculated from an EoS, to take into account the deviations of the saturated vapor from ideal-gas behavior. 2.A Poynting factor since the liquid is at a pressure $P$ different from the one at saturation. This term is related to the difference between the fugacity at standard state conditions, $f_{i}^{L}(T, P)$, and the fugacity at the saturation line, $\left.f_{i}^{L}(T)\right|_{P_{i}^{s a t}}$.

The rigorous form of the Poynting correction requires the calculation the integral term $\int v_{i}^{L} d P$; however a condensed phase at conditions far from critical, may often be regarded as incompressible, and in that case the Poynting term takes a simpler form where the integral term is replaced by the product of an invariant molar volume and the pressures difference between the extremes of integration $P$ and $P_{i}^{\text {sat }}$. This simplified form is the one used in practice, therefore excess Gibbs energy models are applicable as long as this assumption holds ${ }^{4}$. 


\subsection{Theory of un-symmetric standard state}

Gases used in the $\gamma-\varphi$ approach are commonly treated according to the un-symmetric convention, this is because the pure components liquid properties for the given $T$ cannot be measured.

In this section we describe the theory used in the application of the un-symmetric framework. A description is given on how the Henry's law constant at standard conditions and the Henry's law constant at solvent saturation pressure are defined and linked.

For super critical components, relations based on the symmetric approach can only be used by introducing a hypothetical (physically unreal) liquid standard state.

In order to avoid difficulties, whenever the liquid mixture cannot exist over the entire composition range, it is common practice to define excess functions relative to an ideal dilute solution, in line with Henry's law. The condition for ideality requires the ratio of the fugacity to the solute mole fraction being independent on its concentration; which is the case, provided the latter is sufficiently small. Accordingly, for a component under the un-symmetric convention the standard state is specified by unit concentration extrapolated to the limit of infinite dilution.

The Henry's law constant, $H_{g}\left(T, P, \mathbf{n}_{\boldsymbol{k}}\right)_{k \neq g}$, is defined as the limit ratio of the fugacity of the component in the vapor phase and its mole fraction in the solution when the latter tends to zero,

Eq. (2). Its value can be obtained from the one at $T$ and $P_{s o l}^{s a t},\left.H_{g}\left(T, \mathbf{n}_{k}\right)_{k \neq g}\right|_{P_{s o l}^{s a t}}$, applying the Poynting correction, Eq. (3).

$$
\begin{aligned}
& H_{g}\left(T, P, \mathbf{n}_{k}\right)_{k \neq g}=\lim _{x_{g} \rightarrow 0} \frac{\hat{f}_{g}^{V}(T, P, \mathbf{m})}{x_{g}}=\lim _{x_{g} \rightarrow 0} P \hat{\varphi}_{g}^{V}(T, P, \mathbf{m}) \frac{y_{g}}{x_{g}} \\
& H_{g}\left(T, P, \mathbf{n}_{k}\right)_{k \neq g}=\left.H_{g}\left(T, \mathbf{n}_{k}\right)_{k \neq g}\right|_{l_{s o l d}^{\text {sol }}} \exp \left(\frac{1}{R T} \int_{P_{s o l}^{s a t}}^{P} \bar{v}_{g}^{\infty} d P\right)
\end{aligned}
$$


Solubility measurements require two phases always present; as the limit $x_{g} \rightarrow 0$ is approached, $y_{g}$ goes to zero as well, and the pressure of the system tends to the vapor pressure of the solvent alone: $P \rightarrow P_{\text {sol }}^{\text {sat }}$. In this case the extremes of integration in the Poynting correction overlap and the Henry's law constant matches the value at solvent saturation pressure ${ }^{24}$. Measurements of total pressure and composition of both phases are preferably needed, plus the fugacity coefficients from an EoS, Eq. (2).

In the most rigorous way the determination of the Henry's law constant at solvent saturation pressure, requires measurements to the lowest mole fractions possible so as to reduce the extent of extrapolation at $x_{g} \rightarrow 0$; for obvious reasons solubilities are never measured at those conditions.

In order to represent solubility equilibria at different pressures, it is possible to extend the validity of Eq. (2) outside the limit condition of infinite dilution. Krichevsky-Kasarnovsky equation ${ }^{25}$, Eq. (4) can be derived upon combining Eq. (2) and (3), for pure solvent, and by considering $\bar{v}_{g}^{\infty}$ constant with pressure (a reasonable assumption if the solution temperature is well below critical conditions).

$\ln \left(P \hat{\varphi}_{g}^{V}(T, P, \mathrm{~m}) \frac{y_{g}}{X_{g}}\right)=\ln \left(\left.H_{g}(T)\right|_{P_{i}^{\text {sat }}}\right)+\frac{\bar{\nu}_{g}^{\infty}}{R T}\left(P-P_{i}^{\text {sat }}\right) ;$ pure solvent case

The Krichevsky-Kasarnovsky equation is a linear function of pressure: the intercept gives the Henry's law constant at solvent saturation pressure and the slope yields the partial molar volume of the gaseous solute. The equation can be expected to hold for all these cases that conform to the assumptions on which the equation rests ( $x_{g}$ must be small). The approach proved to be remarkably useful for representing solubilities of sparingly soluble gases to very high pressures, e.g. $\mathrm{H}_{2}$ and $\mathrm{N}_{2}$ in water up to 1000 bar or solubilities of about $2 \mathrm{~mol} \%$. 
At larger solubilities, deviations become significant. In those cases, the non-ideality (in the sense of Henry’s law ${ }^{4}$ ) can be accounted using an activity coefficient and replacing $x_{g}$ in Eq. (4) with the product $\gamma_{g}^{*}(T, \mathbf{n}) x_{g}$ which gives.

$\ln \left(P \hat{\varphi}_{g}^{V}(T, P, \mathbf{m}) \frac{y_{g}}{X_{g}}\right)=\ln \left(\left.H_{g}\left(T, \mathbf{n}_{k}\right)_{k \neq g}\right|_{P_{s o l}^{s o t}}\right)+\ln \left(\gamma_{g}^{*}(T, \mathbf{n})\right)+\frac{\bar{v}_{g}^{\infty}}{R T}\left(P-P_{s o l}^{s a t}\right)$

When the two-suffix Margules equation ${ }^{6}$ is used to model the un-symmetric activity coefficient in a pure solvent, the general form of Eq. (5) leads to Krichevsky-Ilinskaya equation, Eq. (6).

$\ln \left(P \hat{\varphi}_{g}^{V}(T, P, \mathrm{~m}) \frac{y_{g}}{x_{g}}\right)=\ln \left(\left.H_{g}(T)\right|_{P_{i}^{s a t}}\right)+\frac{A(T)}{R T}\left(x_{i}^{2}-1\right)+\frac{\bar{v}_{g}^{\infty}}{R T}\left(P-P_{i}^{\text {sat }}\right) ; \quad$ pure solvent case

Krichevsky-Ilinskaya has a wider applicability than Krichevsky-Kasarnovsky equation. However, if gas-solubility data alone are available, it is difficult to obtain all three isothermal parameters $\left(\bar{v}_{g}^{\infty},\left.H_{g}(T)\right|_{P_{i}^{s a t}}, A(T)\right)$ from data reduction.

When $\ln \left(P \hat{\varphi}_{g}^{V}(T, P, \mathbf{m}) y_{g} / x_{g}\right)$ is plotted against $\left(P-P_{i}^{s a t}\right)$, the intercept still gives a good value for the Henry's law constant at solvent saturation pressure. However, since the slope depends on both the second and third term in Eq. (6), it is often not possible to obtain unique values for $\bar{v}_{g}^{\infty}$ and $A(T)$. To separate competing effects, the partial molar volume of the solute should be known from independent measurements, e.g. dilatometric ones ${ }^{5}$, or alternatively estimated through suitable correlations. The trade-off between measurements accuracy, that drops as the infinite dilution condition is approached, and the extent of the extrapolations needed far from the limit behavior is one of the reasons behind the large uncertainties in the estimation of Henry’s law constants; which in fact differ quite significantly from study to study.

The poor quality of the solubility data reported in literature, and the often absent vapor mole fractions (rarely measured along with solubilities), which force to resort $\varphi-\varphi$ or $\gamma-\varphi$ models 
to estimate the equilibrium (vapor) compositions make the estimation of Henry's law constants even more problematic.

\subsection{Links between saturation pressure and Henry's law constant}

Saturation pressures of pure liquids are measured at the very conditions defined by the corresponding saturation lines. In contrast the Henry's law constants at the solvent saturation pressure conditions are calculated (not measured) from low pressure data under simplified assumptions, or obtained from data regression according to the Krichevsky-Kasarnovsky equation, Krichevsky-Ilinskaya equation or Eq. (5). Though the correlation schemes to some extent affect the $\left.H_{g}(T)\right|_{P_{i}^{s a t}}$ values, it is generally possible to get an acceptable estimation, even with great uncertainty on the rest of the parameters $\left(\bar{v}_{g}^{\infty}, A(T)\right.$, or the interaction parameters for the activity coefficient model adopted for Eq. (5)). At this regard, Carroll and Mather ${ }^{5}$ give an example of an hypothetical system that produces a linear trend in the Krichevsky-Kasarnovsky plot. Such behavior makes it difficult to separate the contributions of $\bar{v}_{g}^{\infty}$ and $A(T)$ on the gas solubility (as function of pressure), i.e. the two parameters are nearly indeterminate. Carroll and Mather further report that solubility data showing negative slopes in the KrichevskyKasarnovsky plot have led, not in a few cases, to the erroneous assumption of a negative $\bar{v}_{\mathrm{g}}^{\infty}$.

All things considered, the Henry's law constant at the solvent saturation pressure (that corresponds to the intercept of $\hat{f}_{g}^{V}(T, P, \mathbf{m})$ in the Krichevsky-Kasarnovsky plot), is only partly influenced by the uncertainty on the model parameters. Indeed, $\left.H_{g}(T)\right|_{P_{i}^{s a t}}$ is always explicitly calculated and defined in the limit of infinite dilution where the activity coefficient and Poynting term do not play a role. This attests that the Henry's law constant at the saturation pressure of the solvent it is not a parameter whose value can be freely tuned to improve data fitting of a possibly poor thermodynamic modeling. 
Indeed, $\left.H_{g}(T)\right|_{P_{i}^{s a t}}$ is a property of the un-symmetric state: $\left(T, P_{i}^{s a t}, x_{g} \rightarrow 0\right)$ and just like the symmetric fugacity $\left.f_{i}^{L}(T)\right|_{P_{i}^{s a t}}$, has some fundamental characteristics. $\left.H_{g}(T)\right|_{P_{i}^{s a t}}$ and $\left.f_{i}^{L}(T)\right|_{P_{i}^{s a t}}$ are functions of temperature only, both describe a vapor-liquid equilibrium and they can be correlated with the inverse of temperature in the Van't Hoff plot. The slope of the resulting curves yield respectively: the evaporation enthalpies, or the dissolution enthalpies. For pure liquid saturated vapor pressure, the corresponding expressions are known as Antoine equations, as the most general form adopted by AspenTech ${ }^{26}$ and reported Eq. (7), while the simplest one is the Clausius-Clapeyron relation. For the Henry's law constant in a pure solvent at its saturation pressure, similar functions of temperature are used; e.g. Eq. (8) found in AspenTech software ${ }^{26}$ and applied in several works on gas solubility, it was first developed by Glew ${ }^{27}$.

In this work a truncated form of Eq. (8), using the first three terms, was found appropriate to represent the variation of the Henry's law constant with temperature; also in view of the quality of the data and the consequential uncertainty on the actual value of $\left.H_{g}(T)\right|_{P_{i}^{s a t}}$.

$$
\begin{aligned}
& \ln \left(P_{i}^{\text {sat }} / \text { bar }\right)=p_{1}+\frac{p_{2}}{\left(T+p_{3}\right)}+p_{4} T+p_{5} \ln (T)+p_{6} T^{p_{7}} \\
& \ln \left(\left.H_{g}(T)\right|_{P_{i}^{\text {sat }}} / \text { bar }\right)=h_{1}+\frac{h_{2}}{T}+h_{3} \ln (T)+h_{4} T+\frac{h_{5}}{T^{2}} ; \quad \text { pure solvent case }
\end{aligned}
$$

\subsection{Hypothetical standard state fugacity for supercritical components}

In gas solubility calculations, the gas is often in a supercritical condition and it therefore cannot exist in a condensed state, if not as a solute in a mixture. For the same reason pure saturated vapor pressures do not exist, making it impossible to define the corresponding fugacities at the saturation line, $\left(T, P_{i}^{\text {sat }}\right)$. 
In order to model gas solubility according to the symmetric convention, a hypothetical liquid standard state, which assumes that the pure condensed gas can exist, is formally introduced, $f_{g}^{h y L}(T, P)$. The fugacity of the component in the mixture can, therefore, be equivalently expressed by Eq. (9) or Eq. (10); respectively according to symmetric and the un-symmetric convention.

$\hat{f}_{g}^{V}(T, P, \mathbf{n})=f_{g}^{h y L}(T, P) X_{g} \gamma_{g}(T, \mathbf{n})$

$\hat{f}_{g}^{V}(T, P, \mathbf{n})=H_{g}\left(T, P, \mathbf{n}_{k}\right)_{k \neq g} X_{g} \gamma_{g}^{*}(T, \mathbf{n})$

Equating Eq. (9) and Eq. (10) at the limit of $x_{g} \rightarrow 0$ leads to:

$H_{g}\left(T, P, \mathbf{n}_{k}\right)_{k \neq g} \lim _{x_{g} \rightarrow 0} X_{g} \gamma_{g}^{*}(T, \mathbf{n})=f_{g}^{h y L}(T, P) \lim _{x_{g} \rightarrow 0} X_{g} \gamma_{g}(T, \mathbf{n}) \Rightarrow$

$\frac{H_{g}\left(T, P, \mathbf{n}_{k}\right)_{k \neq g}}{\gamma_{g}^{\infty}\left(T, \mathbf{n}_{k}\right)_{k \neq g}}=f_{g}^{h y L}(T, P)$

Both the symmetric activity coefficient at infinite dilution, $\gamma_{g}^{\infty}\left(T, \mathbf{n}_{k}\right)_{k \neq g}$, and the Henry's law constant, $H_{g}\left(T, \mathbf{n}_{k}\right)_{k \neq g}$, depend on the nature of the solute-solvent interaction. Their ratio, $H_{g}\left(T, P, \mathbf{n}_{k}\right)_{k \neq g} / \gamma_{g}^{\infty}\left(T, \mathbf{n}_{k}\right)_{k \neq g}$, is a property of the gaseous component alone, and it must be identical in any solvent or solvent mixture ${ }^{23}$.

The introduction of $f_{g}^{h y L}(T, P)$, into the left hand side of Eq. (11) yields the relation between symmetric and un-symmetric activity coefficients:

$\frac{\gamma_{g}(T, \mathbf{n})}{\gamma_{g}^{\infty}\left(T, \mathbf{n}_{k}\right)_{k \neq g}}=\gamma_{g}^{*}(T, \mathbf{n})$

Eq. (13) allows for the use of symmetric activity models in the un-symmetric approach. However, the resulting formulas are affected by large uncertainty regarding the parameterization, especially for systems of sparingly soluble gases. This can be exemplified by rewriting Eq. (13) in terms of the three-suffix Margules equations, i.e.: 


$$
\ln \gamma_{g}^{*}(T, \mathbf{n})=1 / R T\left[A_{g i}(T)+2\left(A_{i g}(T)-A_{g i}(T)\right) x_{g}\right] x_{i}^{2}-A_{g i}(T) / R T, \text { with } \ln \gamma_{g}^{\infty}(T)=
$$
$A_{g i}(T) / R T$

$$
\ln \gamma_{i}(T, \mathbf{n})=1 / R T\left[A_{i g}(T)+2\left(A_{g i}(T)-A_{i g}(T)\right) x_{i}\right] x_{g}^{2}
$$

The two expressions are difficult to parametrize, since both $\gamma_{g}^{*}(T, \mathbf{n})$ and $\gamma_{i}(T, \mathbf{n})$ tend to be independent of the model parameters, as $x_{g}$ becomes small. An evidence of this, is the fact that solubilities of $\mathrm{H}_{2}$ and $\mathrm{N}_{2}$ in water up to 1000 bar were correctly described by the KrichevskyKasarnovsky equation; i.e. considering the activity coefficients independent on the solute concertation, $\gamma_{g}^{*}(T, \mathbf{n})=1$ or identically $\gamma_{g}(T, \mathbf{n})=\gamma_{g}^{\infty}(T)$.

Although Eq. (12) does not directly provides $\gamma_{g}^{\infty}\left(T, \mathbf{n}_{k}\right)_{k \neq g}$, since $f_{g}^{h y L}(T, P)$ is generally unknown, the invariability of the ratio $H_{g}\left(T, P, \mathbf{n}_{k}\right)_{k \neq g} / \gamma_{g}^{\infty}\left(T, \mathbf{n}_{k}\right)_{k \neq g}$ across different systems of the same supercritical component enforces an important constraint on the values $\gamma_{g}^{\infty}\left(T, \mathbf{n}_{k}\right)_{k \neq g}$ can assume in the various solvents. This can be exploited during the parametrization of excess Gibbs energy models. By choosing solubility data of the same gas in various solvents and setting up the regressions with the additional constraint of equal $H_{g}\left(T, P, \mathbf{n}_{k}\right)_{k \neq g}$ to $\gamma_{g}^{\infty}\left(T, \mathbf{n}_{k}\right)_{k \neq g}$ ratios for all systems, the model becomes consistent. The proposed method should guarantee more accurate predictions of symmetric activity coefficients at infinite dilution, provided $H_{g}\left(T, P, \mathbf{n}_{k}\right)_{k \neq g}$ values are well determined in all solvents studied.

For reduced temperatures above 1 the exact value of the hypothetical liquid fugacity is ambiguous $^{28}$; yet its value needs to be consistent at least within the same thermodynamic model. In the past only few authors used this principle in order to express the fugacity of the supercritical component in a mixture applying the symmetric framework ${ }^{28,29}$. Its application in 
the customary un-symmetric approach to prevent thermodynamic inconsistency and wrong property prediction of particularly $\gamma_{g}^{\infty}(T)$, has not been used in literature studies.

Comparing the works on gas solubility published over the several last decades, it is evident that there is an enormous discrepancy in the $\gamma_{g}^{\infty}(T)$ values proposed by different studies for the same systems. This is because the iso-fugacity condition written according to the un-symmetric convention involves the normalization of the symmetric activity coefficient using a scaling factor, which is in the limit of infinite dilution, $\gamma_{g}^{\infty}(T)$. As long as the scaled activity coefficient equation preserves the trend required to fit the experimental data, the actual value of the scaling factor, $\gamma_{g}^{\infty}(T)$, has little or no impact on the model performance. The use of a consistent thermodynamic approach, as the one implicit in Eq. (12), could reduce the incongruence among the different studies and thus also the risk of ill-defined parameters.

A related procedure was used by Prausnitz and Shair ${ }^{30}$ and later by McKetta Jr. and Yen ${ }^{31}$. Their aim, however, was to develop a correlation for the fugacity of the hypothetical liquid at the reference pressure of 1 atm, rather than model parameterization. Prausnitz and Shair ${ }^{30}$ derived their scheme based on a thermodynamic cycle; this involved the change in Gibbs energy of the supercritical component going from gas at 1 atm to hypothetical liquid state at the same pressure. The cycle goes through the formation of a mixture where partial molar volumes are considered equal to the ones of the pure components, $\bar{v}_{i}^{L} \cong v_{i}^{L}$ and $\bar{v}_{g}^{L} \cong v_{g}^{h y L}$, so that solvent molar volumes were used, while gas partial molar volumes were fitted. The solvent was considered nonvolatile thus $\left.\left.\hat{f}_{g}^{V}(T, \mathbf{m})\right|_{1 a t m} \cong f_{g}^{V}(T)\right|_{1 a t m}$. The derivation of Eq. (14), as done by Prausnitz and Shair, includes several assumptions. The interesting observation is that the relation reduces to Eq. (12) at $x_{g} \rightarrow 0$, and the approach is therefore consistent at infinite dilution. 
$\ln \left(\left.f_{g}^{h y L}(T)\right|_{1 a t m}\right)=\ln \left(\frac{\left.f_{g}^{V}(T)\right|_{1 a t m}}{x_{g} \gamma_{g}(T, \mathbf{n})}\right)$

Prausnitz and Shair, used the Hildebrand equation to model $\gamma_{g}(T, \mathbf{n})$, leading to the expression that forms the basis of the their method. The coefficients in Eq. (15) are all temperature dependent; however, the theory of regular solutions assumes that, at constant composition, $\left.\ln \gamma_{g}(T)\right|_{\mathbf{n}} \propto 1 / T$. As a result, any temperature may be used to specify molar volumes and solubility parameters. The temperature chosen in their study was conveniently $25^{\circ} \mathrm{C}$.

$\ln \left(\left.f_{g}^{h y L}(T)\right|_{1 a t m}\right)=\ln \left(\left.f_{g}^{V}(T)\right|_{1 a t m}\right)-\ln \left(x_{g}\right)-\frac{\left.\bar{v}_{g}^{L}\right|_{25^{\circ} C}}{R T}\left(\left.\delta_{g}\right|_{25^{\circ} C}-\left.\delta_{i}\right|_{25^{\circ} C}\right)^{2}\left(\frac{\left.x_{i} \bar{v}_{i}^{L}\right|_{25^{\circ} C}}{\left.X_{i} \bar{v}_{i}^{L}\right|_{25^{\circ} C}+\left.x_{g} \bar{v}_{g}^{L}\right|_{25^{\circ} C}}\right)^{2}$

Rather than calculating the fugacities of the hypothetical liquids at $1 \mathrm{~atm}$, individually, for each supercritical component, the theorem of corresponding states was applied to correlate the solubility data of different gases with a single function of reduced properties: $\left[\left.f_{g}^{h y L}(T)\right|_{1 a t m} / P_{g C}\right]=f u n\left(T / T_{g C}\right), g=\left[\mathrm{CO}_{2}, N_{2}, C H_{4}, C O, O_{2}, \ldots\right]$

Prausnitz and Shair used pure vapor-pressure data of liquefied gases, such as $\mathrm{Cl}_{2}, \mathrm{Rn}, \mathrm{CO}_{2}$, to derive the correlation for the fugacity of the hypothetical liquid in the range $0.7<T_{g R}<0.8$. In this range there is no need for gas solubility data in solvents, because gases are condensable and reasonably separated from the critical point.

For the reduced temperature in the range $0.8<T_{g R}<3.2$ they applied Eq. (15) to solubility data (there are only few solubility datasets at $T_{g R}>3.2$ ).

Indeed, $\mathrm{H}_{2}$ is the only gas that, for the temperatures of practical interest, has $T_{g R}>3.2$; however due to its extremely low critical temperature, the solubility data available were not used 
to extend the generalized correlation. In this case $\left.f_{g}^{h y L}(T)\right|_{1 a t m}$ was plotted separately in the temperature range $-40^{\circ} \mathrm{C}$ to $230{ }^{\circ} \mathrm{C}\left(7.0<T_{g R}<15.1\right)$.

Prausnitz and Shair method is applied in the present work in order to obtain the fugacity of the hypothetical liquid at 1 atm used in the parametrization of the thermodynamic model.

\subsection{A new approach for gas solubility in mixed solvents}

A reasonably correct estimate of the solubility of a gas in a simple solvent mixture can be made provided that the solubility of the gas is known in each of the pure solvents that comprise the mixture. The method is discussed by O’Connell and Prausnitz ${ }^{32}$. It is based on the Wohl expansion ${ }^{4}$, and for two component solvents leads to the well-known Eq. (16).

$$
\ln \left(H_{g}\left(T, P, \mathbf{n}_{k}\right)_{k \neq g}\right)=X_{i} \ln \left(\underset{\substack{g \\ \text { solvent }-i}}{H_{k}(T, P)}\right)+X_{j} \ln \left(\underset{\substack{g \\ \text { solvent }-j}}{H_{j}(T, P)}\right)-\alpha(T) X_{i} X_{j}
$$

The parameter $\alpha(T)$ is obtained from vapor-liquid equilibrium data for the binary solution of the solvents in the absence of the gaseous solute, using the two-suffix Margules equations, Eq. (17). The equations can be generalized to multicomponent solvents as well.

$$
\ln \gamma_{i}(T, \mathbf{n})=\frac{A(T)}{R T} X_{j}^{2} ; \quad \ln \gamma_{j}(T, \mathbf{n})=\frac{A(T)}{R T} X_{i}^{2} ; \quad \alpha(T)=\frac{A(T)}{R T}
$$

The derivation of Eq. (16) relies on the exactness of two-suffix Margules equations. This expression assumes that only two-body interactions contribute significantly to the excess free energy of the ternary mixture and that the characteristic coefficients for these interactions are given by empirical constants as determined from binary data. Such simplified picture of a liquid solution cannot be expected to have general validity but it should be a good approximation for solutions consisting of simple nonpolar molecules.

Here we suggest a method for the prediction of gas solubility in mixed solvents whose theoretical derivation does not resort to any model. Indeed, $\gamma_{g}^{\infty}\left(T, \mathbf{n}_{k}\right)_{k \neq g}$ is considered 
independent of pressure; however the analysis is equally valid when this assumption is not introduced. The relation here proposed is intrinsic to Eq. (12).

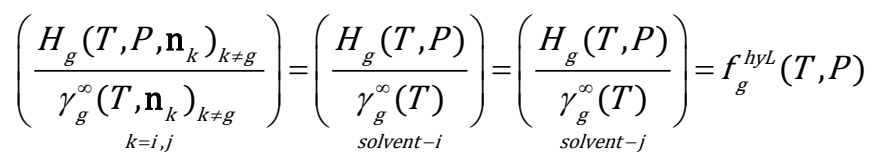

Provided the Henry's law constants in two pure solvents and the coefficients for the excess Gibbs energy model are known, Eq. (18) allows the calculation of $H_{g}\left(T, P, \mathbf{n}_{k}\right)_{k \neq g}$ for the ternary mixture. The required coefficients can be determined by the regression of binary data alone (gas-solvent- $i$, gas-solvent- $j$, solvent- $i$-solvent- $j$ ). By implementing, in the model parameter estimation, the constraint proposed in section 2.4, thermodynamic inconsistencies would be avoided when Eq. (18) is applied (i.e. all the equalities will be respected). Eq. (18) is written for two solvents mixture ( $i$ and $j$ ), but applies unchanged to the multicomponent case.

\section{VLE calculations}

The $\gamma-\varphi$ approach is known for its ability to describe both the vapor and liquid phases by representing the liquid phase with a solution model and the vapor phase with an EoS. For a binary system of a supercritical component in a pure solvent, the equations describing the equilibrium condition with this approach are the following:

$y_{g} \hat{\varphi}_{g}^{V}(T, P, \mathbf{m}) P=\left.x_{g} \frac{\gamma_{g}(T, \mathbf{n})}{\gamma_{g}^{\infty}(T)} H_{g}(T)\right|_{P_{i}^{\text {sat }}} \exp \left[\frac{\bar{v}_{g}^{\infty}\left(P-P_{i}^{\text {sat }}\right)}{R T}\right]$
$y_{i} \hat{\varphi}_{i}^{V}(T, P, \mathbf{m}) P=\left.x_{i} \gamma_{i}(T, \mathbf{n}) P_{i}^{\text {sat }} \varphi_{i}(T)\right|_{P_{i}^{s a t}} \exp \left[\frac{U_{i}^{L}\left(P-P_{i}^{s a t}\right)}{R T}\right]$

The UNIQUAC model ${ }^{33}$ was chosen to model the activity coefficients. This model accounts for both size/shape differences between molecules and energetic interactions via Eq. (21)-(24): $\ln \left(\gamma_{i}(T, \mathbf{n})\right)=\ln \left(\gamma_{i}^{C}(\mathbf{n})\right)+\ln \left(\gamma_{i}^{R}(T, \mathbf{n})\right)$ 


$$
\begin{aligned}
& \ln \left(\gamma_{i}^{C}(\mathbf{n})\right)=\left[1-\frac{\Phi_{i}(\mathbf{n})}{x_{i}}+\ln \left(\frac{\Phi_{i}(\mathbf{n})}{X_{i}}\right)\right]-5 q_{i}\left[1-\frac{\Phi_{i}(\mathbf{n})}{\theta_{i}(\mathbf{n})}+\ln \left(\frac{\Phi_{i}(\mathbf{n})}{\theta_{i}(\mathbf{n})}\right)\right] ; \quad \Phi_{i}(\mathbf{n})=\frac{x_{i} r_{i}}{\sum_{i} X_{i} r_{i}} ; \quad \theta_{i}(\mathbf{n})=\frac{X_{i} q_{i}}{\sum_{i} X_{i} q_{i}} \\
& \ln \left(\gamma_{i}^{R}(T, \mathbf{n})\right)=q_{i}\left[1-\ln \left(\sum_{j} \theta_{j}(\mathbf{n}) \tau_{j i}(T)\right)-\sum_{j} \frac{\theta_{j}(\mathbf{n}) \tau_{i j}(T)}{\sum_{k} \theta_{k}(\mathbf{n}) \tau_{k j}(T)}\right] ; \quad \tau_{i j}(T)=\exp \left(\frac{-\Delta u_{i j}(T)}{R T}\right)
\end{aligned}
$$

The volume and the surface fractions of the components in the mixture, respectively $\Phi_{i}(\mathbf{n})$ and $\theta_{i}(\mathbf{n})$, are obtained from the components size and surface parameters $r_{i}$ and $q_{i}$ which are estimated from the Bondi group contribution method ${ }^{34}$. The values are dimensionless; the groups are normalized using a methylene unit as reference $\left(15.17 \mathrm{~cm}^{3} / \mathrm{mol}\right.$ and $\left.2.5 \cdot 10^{9} \mathrm{~cm}^{2} / \mathrm{mol}\right)$. The UNIQUAC delta interaction coefficients ${ }^{33}, \Delta u_{i j}(T)$ and $\Delta u_{j i}(T)$, are calculated from differences in interaction parameters, $u_{i i}(T), u_{j j}(T)$ and $u_{i j}(T)=u_{j i}(T)$, Eq. (24).

$$
\Delta u_{i j}(T)=u_{i j}(T)-u_{i j}(T) ; \quad \Delta u_{j i}(T)=u_{j i}(T)-u_{i i}(T)
$$

The interaction parameters, which characterize the potential between two nearest-neighbor molecules, can be expressed as function of temperature in different forms. Two examples are given below; $T_{0}$ is a convenient reference temperature. Eq. (25)-(26) are equivalent, and in Appendix A, Eq. (A1) are listed the relevant conversions.

$$
\begin{aligned}
& u(T)=u_{T 0}+u_{T 1}\left(T-T_{0}\right)+u_{T 2}\left(T-T_{0}\right)^{2}+u_{T 3} T \ln \left(\frac{T}{T_{0}}\right) \\
& u(T)=u_{a}^{\prime} T+u_{b}^{\prime}+u_{c}^{\prime} T \ln (T)+u_{d}^{\prime} T^{2}
\end{aligned}
$$

Peng-Robinson EoS ${ }^{35}$ with the classical mixing rules was used to model the vapor phase nonideality in order to obtain the necessary fugacity contributions, $\hat{\varphi}_{g}^{V}(T, P, \mathbf{m}), \hat{\varphi}_{i}^{V}(T, P, \mathbf{m})$ and

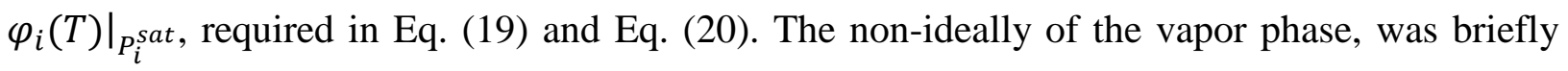
considered, but the introduction of non-zero binary interaction parameters in the EoS did not 
have appreciable effect on the quality of the optimization. Peng-Robinson EoS ${ }^{35}$ is reported in Appendix A, Eq. (A2)-(A4).

The Hayden-O'Connell Virial EoS ${ }^{36}$ was used in cases of systems containing acetic acid. The method predicts the second Virial coefficient by using contributions which can account for the polar and associating interactions, Appendix A, Eq. (A5)-(A24).

In all cases the most accurate gas phase model was used, without any tuning. Only binary solubility data were used and only the UNIQUAC interaction parameters were fitted. In principle, any gas phase model can be coupled with UNIQUAC, as long as the vapor phase is correctly represented. The use of Hayden-O'Connell Virial EoS ${ }^{36}$ for systems containing acetic acid (rather than a cubic EoS) is owed to the fact that this component shows a monomer-dimer equilibrium in the vapor phase, and this complex association behavior cannot be predicted by the PR or Soave-Redlich-Kwong (SRK) EoS (in unmodified form). However, Hayden-O'Connell is a Virial EoS truncated at the second coefficient, and this restricts its applicability to moderate vapor densities only.

The saturation pressure for the pure solvent $P_{i}^{\text {sat }}$ and the Henry's law constant at the solvent saturation pressure $\left.H_{g}(T)\right|_{P_{i}^{\text {sat }}}$ are given respectively by Eq. (7) and Eq. (8) truncated at the third term.

The volume of the solvent at saturation condition, $v_{i}^{L}$, is obtained from the DIPPR-105 Appendix A, Eq. (A25), and from DIPPR-116 Appendix A, Eq. (A26) for water ${ }^{37}$.

The volume of the solute at infinite dilution $\bar{v}_{g}^{\infty}$ is taken from Brelvi and O’Connell correlation ${ }^{38}$, Appendix A, Eq. (A27)-(A29); as for $v_{i}^{L}, \bar{v}_{g}^{\infty}$ it is assumed pressure independent. 


\section{Model parameter estimation}

Experimental data were mainly taken from the original papers and from the IUPAC-NIST solubility data series. An overview of the data used for the evaluation of model parameters and relative references are given in the supporting information. Points at pressures above 400 bar and temperatures above $90 \%$ of the solvent critical temperature were not included in the regressions. Vapor compositions were not considered as well, they are available in only a few cases.

Low pressure constants, such as Bunsen coefficients, Ostwald coefficients and absorption coefficients, were converted to mole fraction solubility. These units were originally obtained applying ideal gas law, Raoult’s law and Henry's law on the actual measured values; the same assumptions were used to back-calculate mole fractions and total pressure. Occasionally experimental points were given in graphic form only and they were then extracted from the figures.

The only constants involved in the parameter fitting are $h_{1}, h_{2}$ and $h_{3}$ for the Henry's law constant at the saturation pressure of the solvent, Eq. (8); and $u_{a}^{\prime}$ and $u_{b}^{\prime}$ for the interaction parameters of the UNIQUAC model, Eq. (26).

Unlike the Krichevsky-Ilinskaya and Krichevsky-Kasarnovsky approach, the volume of the gas at infinite dilution is not a parameter involved in the regression; Instead the Brelvi and O’Connell correlation ${ }^{38}$, Appendix A, Eq. (A27)-(A29) is used to obtain $\bar{v}_{g}^{\infty}$ as function of temperature. Inaccurate predictions of $\bar{v}_{g}^{\infty}$ may affect the quality of the fitting, particularly at high pressures. Therefore data above 400 bar have not been included. Points at temperatures above $90 \%$ of the solvent critical temperature were not considered either, since the simplified form of the Poynting corrections becomes unreliable (close to $T_{i C}$, the two liquid volumes, $\bar{v}_{g}^{\infty}$ and $v_{i}^{L}$, can no longer be considered incompressible). 
UNIQUAC equation is often fitted to binary data in terms of delta interaction coefficients $\left(\Delta u_{i j}(T)\right.$ and $\left.\Delta u_{j i}(T)\right)$; and these, are the ones found in AspenTech software databanks ${ }^{26}$ and in the DECHEMA Chemistry Data Series ${ }^{39}$. The 15 binary systems object of this study share common components, therefore the independent estimation of the corresponding 15 coefficient pairs would most likely produce model inconsistency; i.e. the coefficient pairs would not satisfy closure equations such as $\left[\Delta u_{i k}(T)-\Delta u_{k i}(T)\right]=\left[\Delta u_{i j}(T)-\Delta u_{j i}(T)\right]+\left[\Delta u_{j k}(T)-\Delta u_{k j}(T)\right]$. This equation, in conjunction with Eq. (24) , implies the invariance of the self-interaction parameters $u_{i i}(T), u_{j j}(T)$ and $u_{k k}(T)$.

To ensure model consistency, the regression was performed in terms of interaction parameters $\left(u_{i i}(T), u_{j j}(T)\right.$ and $\left.u_{i j}(T)=u_{j i}(T)\right)$; which reduces the number of parameter required from 30 to 22. From $15 \Delta u_{g i}$ and $15 \Delta u_{i g}$ (delta interaction coefficients pairs) down to $15 u_{g i}=u_{g i}$ (gassolvent interaction parameters), $5 u_{g g}$ (gas-gas self-interaction parameters), and $3 u_{i i}$ (solventsolvent self-interaction parameters). The $\mathrm{H}_{2} \mathrm{O}-\mathrm{H}_{2} \mathrm{O}$ self-interaction parameter was set to zero as done in Thomsen et al. ${ }^{40}$. This influences the numerical value for the remaining terms, but not the value of the delta interaction coefficients, as they are calculated as differences, Eq. (24).

The use of a reduced set of parameters has also the advantage of narrowing the confidence interval and reducing the risk of an over-parametrized model (less ambiguity on the delta interaction coefficients). Small losses in fitting accuracy are to be expected.

The evaluation of the constants which determine the temperature dependence of the Henry's law constant at the saturation pressure of the solvent and the UNIQUAC interaction parameters, respectively Eq. (8) and Eq. (26), was executed with Levenberg-Marquardt algorithm by minimization of the objective function reported in Eq. (27)-(29). All experimental points producing deviations higher than a certain threshold were not included in the final regression. 
The form of Eq. (27) is implemented to control the weight of the residuals for each data series, and to heighten the contribution of the data points at high concentration compared to those at lower on the objective function value.

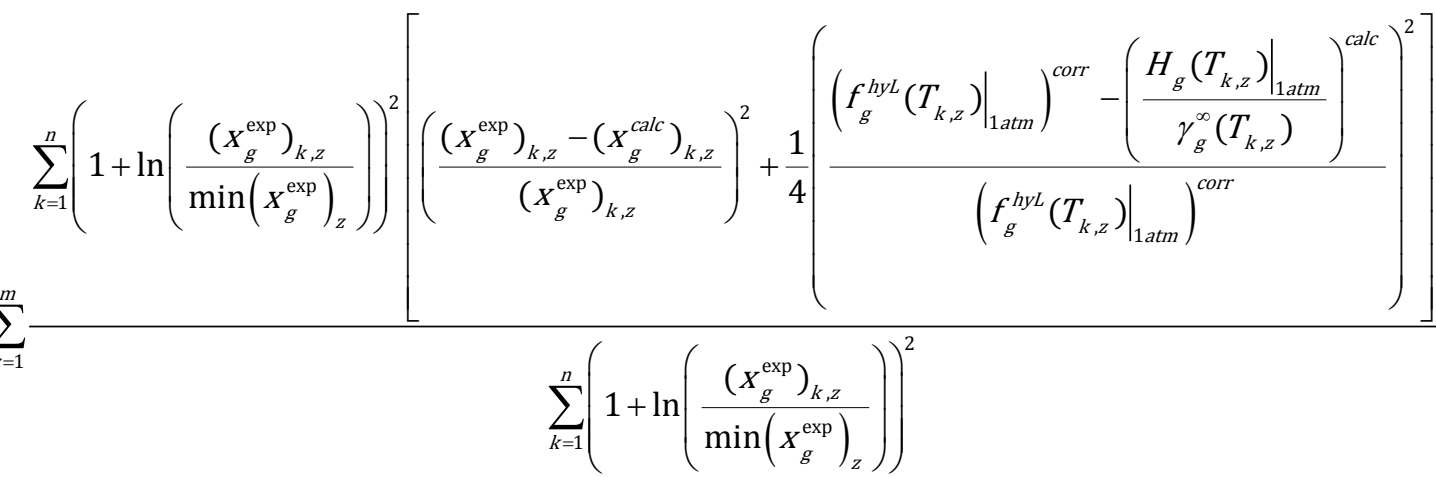

$$
\begin{aligned}
& T_{k, z}=\min \left(T^{\exp }\right)_{z}+(k-1)\left(\frac{\max \left(T^{\exp }\right)_{z}-\min \left(T^{\exp }\right)_{z}}{n-1}\right) \\
& \left.H_{g}(T)\right|_{1 a t m}=\left.H_{g}(T)\right|_{P_{i}^{\text {sat }}} \exp \left[\frac{\bar{v}_{g}^{\infty}\left(1 \mathrm{~atm}-P_{i}^{\text {sat }}\right)}{R T}\right]
\end{aligned}
$$

The index $k=[1, \ldots, n]$ indicates the data point, $z$ is the binary system index $z=[1, \ldots, m]$ (e.g. $z=1$ corresponds to $\mathrm{CO}_{2}-\mathrm{H}_{2} \mathrm{O}$ system, $z=2$ correspond to $\mathrm{CO}_{2}-\mathrm{C}_{2} \mathrm{H}_{5} \mathrm{OH}$ system, etc.).

Eq. (27) includes two residuals: 1.A relative deviation on solute mole fraction, $\left[\left(\left(x_{g}^{e x p}\right)_{k, z}-\left(x_{g}^{c a l c}\right)_{k, z}\right) /\left(x_{g}^{e x p}\right)_{k, z}\right]$. 2.A relative deviation on the fugacity of the hypothetical liquid, $\left[\left(\left.f_{g}^{h y L}\left(T_{k, z}\right)\right|_{1 a t m}\right)^{\text {corr }}-\left(\left.H_{g}\left(T_{k, z}\right)\right|_{1 a t m} / \gamma_{g}^{\infty}\left(T_{k, z}\right)\right)^{\text {calc }} /\left(\left.f_{g}^{h y L}\left(T_{k, z}\right)\right|_{1 a t m}\right)^{\text {corr }}\right]$.

Reducing the difference between $\left.H_{g}(T)\right|_{1 a t m} / \gamma_{g}^{\infty}(T)$ and $\left.f_{g}^{h y L}(T)\right|_{1 a t m}$, obtained from the Prausnitz and Shair correlation, helps reducing the uncertainty on model parameters, especially for those systems where the supercritical component show very low solubility. The approach also prevents thermodynamic inconsistencies when the model is used to calculate gas solubility in mixed solvents according to Eq. (18). 
The terms $\left.f_{g}^{\text {hyL }}(T)\right|_{1 a t m},\left.H_{g}(T)\right|_{1 a t m}$, and $\gamma_{g}^{\infty}(T)$, are evaluated at $T_{k, z}$, these temperature are taken evenly spaced in the same range and in an equal number to the experimental ones, Eq. (28) . The Henry's law constant at 1 atm, $\left.H_{g}(T)\right|_{1 a t m}$, is obtained from the corresponding value at the solvent saturation pressure, $\left.H_{g}(T)\right|_{P_{i}^{s a t}}$, by multiplication with the appropriate Poynting corrections, Eq. (29).

The Prausnitz and Shair method was used to estimate $\left.f_{g}^{h y L}(T)\right|_{1 a t m}$ and a weighting factor of $1 / 4$ was applied to the corresponding deviations, Eq. (27), as the uncertainty of these correlations is unknown. The ambiguity on $\left.f_{g}^{h y L}(T)\right|_{1 a t m}$ values is fully appreciated in the comparative plot reported in Nocon et al. for $\mathrm{CH}_{4}{ }^{28}$. The estimates of the different authors diverge considerably already for the reduced temperature of 1.2; for reduced temperatures of more than 1.7 the relative differences can be higher than 100\%.

A logarithmic weighting was introduced in the objective function to increase the influence on the regression of experimental points at the higher concentrations, $\left[1+\ln \left(\frac{\left(\mathrm{x}_{\mathrm{g}}^{\mathrm{exp}}\right)_{\mathrm{k}, \mathrm{z}}}{\min \left(\mathrm{x}_{\mathrm{g}}^{\mathrm{exp}}\right)_{\mathrm{z}}}\right)\right]^{2}$.

Considering that, in general, there are fewer experimental points at the higher concentrations; the weighting function should ensure a more homogeneous quality in the data fitting over the whole solubility range, which can extend over 3 or 4 orders of magnitude. In addition, because experimental errors are often not available, points at higher concentration may be considered to have lower uncertainties.

Representing the UNIQUAC delta interaction coefficients in terms of interaction parameters makes them interdependent; hence it is required to incorporate in a single regression the 
experimental points relevant to all 15 systems. Each contribution is normalized using the summation of the weights.

The numbers of points involved in the model parameter estimation are given in table format as supporting information.

\section{Modelling results}

The parameter values, obtained as solution of the minimization problem, Eq. (27), are reported in Table 1. The first two columns list the constants, $u_{T 0}$ and $u_{T 1}$, for the temperature dependent UNIQUAC interaction parameters, Eq. (25), both for unlike and self-interactions.

The values reported in Table 1 for $u_{T 0}$ and $u_{T 1}$ are not limited to the particular EoS that has been implemented in the parametrization procedure. In principle, UNIQUAC equation, with the adoption of these constants, can be used in combination with any gas phase model, provided the vapor phase is correctly represented by the EoS chosen.

The regression of the UNIQUAC model in terms of interaction parameters, rather than delta interaction coefficients, has the advantage of exposing trends that otherwise would not be evident. For instance, it can be seen that, for the same supercritical component, $u_{T 1}$ is, in all cases, smaller in magnitude for the systems containing water, and larger for the systems containing ethanol as solvent. It can also be observed that $u_{T 0}$ has similar values for systems of the same gas in ethanol and in acetic acid, but a very different value for systems where the solvent is water.

In Table 1, from the third to fifth column, are listed the coefficients for the temperature dependent Henry's law constant, Eq. (8). For $\mathrm{CH}_{4}-\mathrm{CH}_{3} \mathrm{COOH}$ system the available experimental points cover a rather small temperature range, from 298 to $348 \mathrm{~K}$, thus only two coefficients were subjected to parametrization. 
The last two columns report the Absolute average deviations (AAD\%) for $x_{g}$ and $\left.f_{g}^{h y L}(T)\right|_{1 a t m}$, respectively calculated as $1 / n \sum_{k=1}^{n}\left|\left(\left(x_{g}^{\text {exp }}\right)_{k}-\left(x_{g}^{\text {calc }}\right)_{k}\right) /\left(x_{g}^{\text {exp }}\right)_{k}\right|$, $1 / n \sum_{k=1}^{n}\left|\left(\left.f_{g}^{h y L}\left(T_{k}\right)\right|_{1 a t m}\right)^{\text {corr }}-\left(\left.H_{g}\left(T_{k}\right)\right|_{1 a t m} / \gamma_{g}^{\infty}\left(T_{k}\right)\right)^{\text {calc }} /\left(\left.f_{g}^{h y L}\left(T_{k}\right)\right|_{1 a t m}\right)^{\text {corr }}\right|, \quad$ the $\left.f_{g}^{h y L}\left(T_{k}\right)\right|_{1 a t m}$ values are the ones from Prausnitz and Shair correlation.

Table 1: Temperature dependent constants for UNIQUAC interaction parameters ${ }^{33}$, Eq. (25) .Temperature dependent parameters for Henry's law constant, Eq. (8); the equation gives the Henry's law constant at solvent saturation pressure in bar when the temperature is expressed in $\mathrm{K}$. Temperature and pressure range of the data points involved in the regression. Absolute average deviations, (AAD\%), for $x_{g}$ and $\left.f_{g}^{h y L}(T)\right|_{1 a t m}$

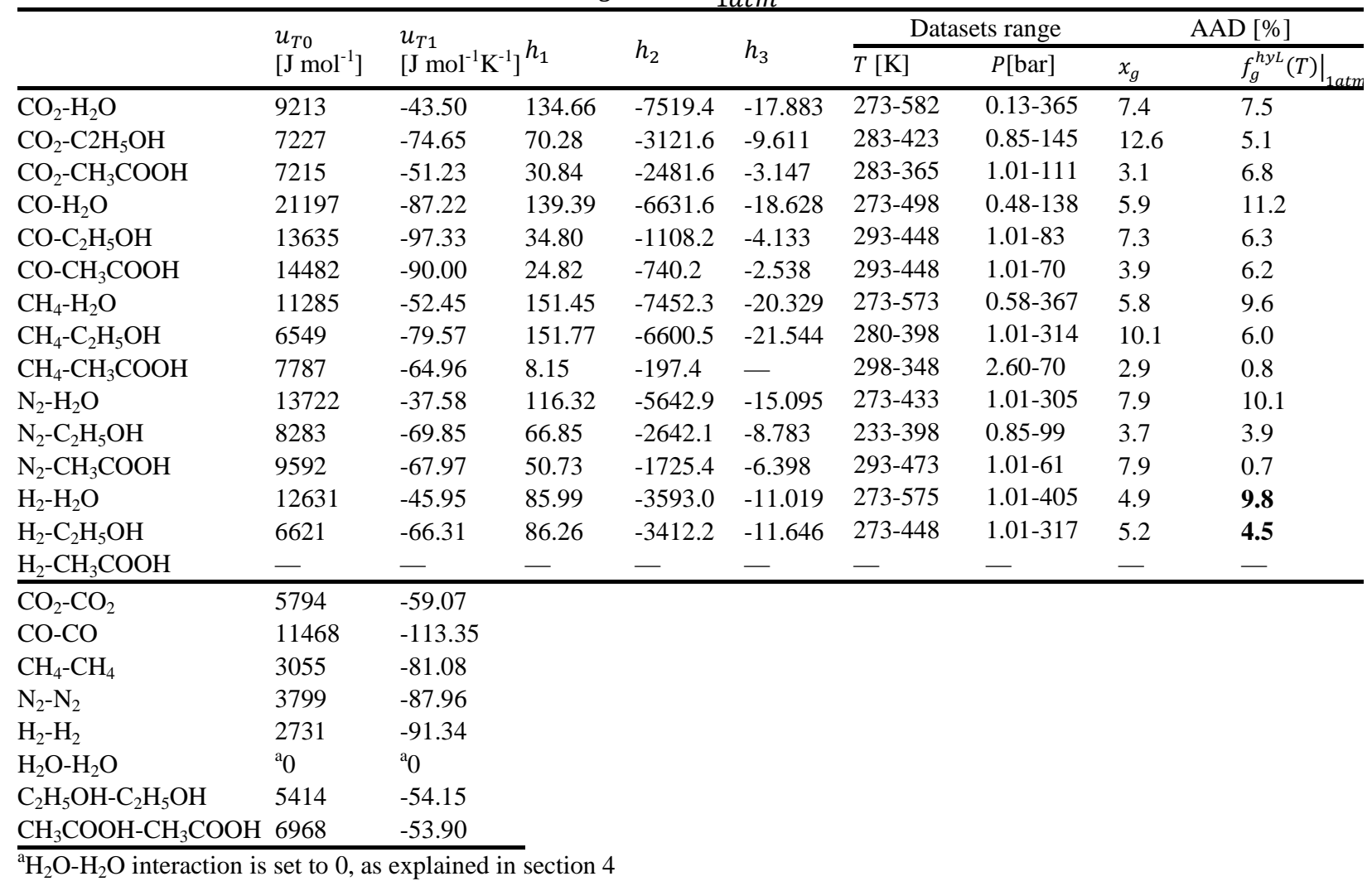

For the solubilities of $\mathrm{H}_{2}$ in $\mathrm{CH}_{3} \mathrm{COOH}$ above 1 atm the only study available is Jónasson at all

41 . The experimental points from this source are, however, not in agreement with the datasets at atmospheric pressure listed in the two other sources found: Maxted and Moon ${ }^{42}$ and Just ${ }^{43}$. Due to the impossibility to confirm the exactness of Jónasson at all results, the system $\mathrm{H}_{2}-\mathrm{CH}_{3} \mathrm{COOH}$ 
was not included in the data regression. For reference purposes, the relevant literature information are reported in Table 15 in the supporting information.

Table 2: Pure component parameters for Peng-Robinson EoS ${ }^{35}$, Appendix A, Eq. (A2)-(A4), and Hayden-O'Connell Virial EoS ${ }^{36}$, Appendix A, Eq. (A5)-(A24)

\begin{tabular}{lllllllll}
\hline & $\mathrm{CO}_{2}$ & $\mathrm{CO}$ & $\mathrm{CH}_{4}$ & $\mathrm{~N}_{2}$ & $\mathrm{H}_{2}$ & $\mathrm{H}_{2} \mathrm{O}$ & $\mathrm{C}_{2} \mathrm{H}_{5} \mathrm{OH}$ & $\mathrm{CH}_{3} \mathrm{COOH}$ \\
\hline$T_{C}[\mathrm{~K}]$ & 304.2 & 132.9 & 190.6 & 126.2 & 33.2 & 647.1 & 514.0 & 591.9 \\
$P_{C}[\mathrm{bar}]$ & 73.8 & 35.0 & 46.00 & 34.0 & 13.1 & 220.6 & 61.4 & 57.9 \\
$\omega$ & 0.2236 & 0.0482 & 0.0115 & 0.0377 & -0.2160 & 0.3449 & 0.6436 & - \\
$r^{\text {gir }}[\mathrm{m}]$ & $1.04 \cdot 10^{-10}$ & $5.58 \cdot 10^{-11}$ & $1.12 \cdot 10^{-10}$ & $5.47 \cdot 10^{-11}$ & - & - & - & $2.61 \cdot 10^{-10}$ \\
$\mu[\mathrm{D}]$ & 0 & 0.1121 & 0 & 0 & - & - & - & 1.7388 \\
\hline
\end{tabular}

Table 2 reports the pure component parameters adopted in Peng-Robinson EoS and HaydenO'Connell Virial EoS for the modeling of the vapor phase. The mean radius of gyrations, $r^{\text {gir }}$, are obtained from the molecular moments of inertia and the molecular masses as described in Hayden and O'Connell paper.

Table 3: Association parameters for pure interactions, $\eta_{i i}$, and solvation parameter for unlike interactions, $\eta_{i j}$, for Hayden-O'Connell Virial EoS ${ }^{36}$, Appendix A, Eq. (A5)-(A24)

\begin{tabular}{llllll}
\hline$\eta_{i i} / \eta_{i j}$ & $\mathrm{CH}_{3} \mathrm{COOH}$ & $\mathrm{CO}_{2}$ & $\mathrm{CO}$ & $\mathrm{CH}_{4}$ & $\mathrm{~N}_{2}$ \\
\hline $\mathrm{CH}_{3} \mathrm{COOH}$ & ${ }^{\mathrm{a}} .5$ & 0.5 & 0 & 0 & 0 \\
$\mathrm{CO}_{2}$ & - & 0.16 & 0 & 0 & 0 \\
$\mathrm{CO}$ & - & - & 0 & 0 & 0 \\
$\mathrm{CH}_{4}$ & - & - & - & 0 & 0 \\
$\mathrm{~N}_{2}$ & - & - & - & - & 0 \\
\hline
\end{tabular}

${ }^{\mathrm{a}}$ The equilibrium constant for acetic acid association reaction as function of temperature is $K_{i i}(T)=\exp (7290 / T-17.36)$

Table 3 lists the relevant values for $\eta_{i i}$ and $\eta_{i j}$, from ${ }^{44}$. Since the association parameters, $\eta_{i i}$, for acetic the acid is equal to 4.5, the equilibrium constant of the dimerization reaction is here given as well; indeed the second Virial coefficient for this interaction, is calculated according to the chemical theory of dimerization, Appendix A, Eq. (A24).

Table 4 reports volumes and surface area parameters used in the UNIQUAC model; those constants are dimensionless. For water, $r$ and $q$ values, were those assigned by Abrams and 
Prausnitz ${ }^{33}$; while, for the remaining molecules, the values were obtained from the Bondi contribution method ${ }^{34}$.

Table 4: Pure component parameters, $r$ and $q$ for UNIQUAC model ${ }^{33}$ from Bondi contribution method ${ }^{34}$, Eq (21)-(23). Characteristic volumes for Brelvi-O’Connell correlation ${ }^{38}$, Appendix A, Eq. (A27)-(A29)

\begin{tabular}{|c|c|c|c|c|c|c|c|c|}
\hline & $\mathrm{CO}_{2}$ & $\mathrm{CO}$ & $\mathrm{CH}_{4}$ & $\mathrm{~N}_{2}$ & $\mathrm{H}_{2}$ & $\mathrm{H}_{2} \mathrm{O}$ & $\mathrm{C}_{2} \mathrm{H}_{5} \mathrm{OH}$ & $\mathrm{CH}_{3} \mathrm{COOH}$ \\
\hline$q$ & 1.292 & 1.112 & 1.152 & 1.088 & 0.870 & 1.400 & 1.972 & 2.072 \\
\hline$r$ & 1.2986 & 1.0679 & 1.1239 & 1.0415 & 0.7940 & 0.9200 & 2.1056 & 2.1951 \\
\hline$v_{C}^{\prime}\left[\mathrm{cm}^{3} / \mathrm{mol}\right]$ & 94.0 & 94.4 & 98.6 & 89.2 & 64.15 & 46.32 & 157.58 & 155.94 \\
\hline
\end{tabular}

Initially, for the two systems $\mathrm{H}_{2}-\mathrm{H}_{2} \mathrm{O}$ and $\mathrm{H}_{2}-\mathrm{C}_{2} \mathrm{H}_{5} \mathrm{OH}$, it was not possible to simultaneously fit, within an acceptable tolerance, both solubility data and fugacity of hypothetical liquid $\mathrm{H}_{2}$ at 1 atm (as obtained from Prausnitz and Shair correlation). Indeed, it was found that the value of $1.20 \AA$, assigned by Bondi ${ }^{34}$ to the Van der Waals radius of hydrogen atoms and typically used to calculate $r$ and $q$ for organic molecules, was not appropriate for the estimation of $r$ and $q$ in $\mathrm{H}_{2}$ molecule. A larger radius appeared to be the only way to obtain satisfactory results.

The Batsanov study on the hydrogen radii in different gas phase and condensed molecules ${ }^{45}$ certainly indicates the great variability in dimensions of this element in relation to the electronegativity of the atom at which is directly bonded. This might be explained considering that hydrogen has only one occupied orbital and only one electron; the extent of the delocalization of this single electron, when involved in the formation of a covalent bond, strongly affects the size of the electron cloud around the hydrogen nucleus.

Based on this evidence, the $r$ and $q$ parameters listed in Table 4, in bold, were calculated using a Van der Waals radius of $1.52 \AA$, as reported for hydrogen atoms specifically for $\mathrm{H}_{2}$ molecule in the Batsanov study ${ }^{45}$. Whit the new coefficients, was possible to reduce the AAD\% on the fugacity of hypothetical liquid $\mathrm{H}_{2}$ at 1 atm pressure to the final values reported in Table 1 , in bold. 
In Table 4 are also listed the characteristic volumes, $v_{C}^{\prime}$, used in Brelvi-O’Connell correlation for estimating $\bar{v}_{g}^{\infty}$ in the different solvents, Appendix A, Eq. (A27)-(A29). For all gases, $v_{C}^{\prime}$ was considered equal to the critical volume of the substance, since, for nonpolar species, $v_{C}^{\prime} / v_{C} \cong 1$, ${ }^{38}$. For polar substances, such as water, acetic acid and ethanol, $v_{C}^{\prime}$ tend to be smaller than $v_{C}$ and the assumption $v_{C}^{\prime} / v_{C} \cong 1$ can no longer be considered correct, especially when $v_{C}$ is that of the solvent (e.g. for water, the use of critical volume, in place of the characteristic volume, can lead to underestimations of $\bar{v}_{g}^{\infty}$ as large as $50 \%$ ). The value reported in Table 4 for water is the one assigned by Brelvi and O’Connell ${ }^{38}$. For ethanol, $v_{C}^{\prime}$ was determined by fitting Appendix A, Eq. (A29) to the density and to the isothermal compressibility data reported in ${ }^{46}$ and ${ }^{47}$; and for acetic acid was obtained by fitting Appendix A, Eq. (A1) only to the isothermal density datasets reported in ${ }^{48}$.

Table 5: Coefficients for the AspenTech extended Antoine equation ${ }^{26}$, Eq. (7); the equation gives the saturation pressure in bar when the temperature is expressed in $\mathrm{K}$

\begin{tabular}{llllllll}
\hline & $p_{1}$ & $p_{2}$ & $p_{3}$ & $p_{4}$ & $p_{5}$ & $p_{6}$ & $p_{7}$ \\
\hline $\mathrm{H}_{2} \mathrm{O}$ & 62.1361 & -7258.2 & 0 & 0 & -7.3037 & $4.1653 \cdot 10^{-6}$ & 2 \\
$\mathrm{C}_{2} \mathrm{H}_{5} \mathrm{OH}$ & 61.7911 & -7122.3 & 0 & 0 & -7.1424 & $2.8853 \cdot 10^{-6}$ & 2 \\
$\mathrm{CH}_{3} \mathrm{COOH}$ & 41.7571 & -6304.5 & 0 & 0 & -4.2985 & $8.8865 \cdot 10^{-18}$ & 6 \\
\hline
\end{tabular}

Table 6 lists the correlation coefficients for estimating the liquid volumes of the solvents at saturated condition. DIPPR-105, Appendix A, Eq. (A25), has the same form of Rackett equation ${ }^{49}$, e.g. $l_{3}$ is the critical temperature of the substance, however the values for the other parameters are generally different from the physical properties they represent in the actual Rackett equation. DIPPR-116 is commonly used for water ${ }^{37}$.

Table 6: Coefficients for liquid saturated volumes, the correlation parameters give the molar volumes in $\mathrm{cm}^{3} \mathrm{~mol}^{-1}$ when the temperature is expressed in $\mathrm{K}$, Appendix A, Eq. (A25)-(A26)

\begin{tabular}{llllll}
\hline & $l_{1}$ & $l_{2}$ & $l_{3}$ & $l_{4}$ & $l_{5}$ \\
\hline $\mathrm{H}_{2} \mathrm{O}$ (DIPPR-116) & 0.017863 & 0.05860 & -0.095396 & 0.21389 & -0.14126 \\
$\mathrm{C}_{2} \mathrm{H}_{5} \mathrm{OH}$ (DIPPR-105) & 0.001629 & 0.27469 & 514 & 0.23178 & \\
$\mathrm{CH}_{3} \mathrm{COOH}$ (DIPPR-105) & 0.001448 & 0.25892 & 591.95 & 0.25290 & \\
\hline
\end{tabular}




\section{Discussion}

Some results of the VLE data correlation are illustrated in Figures from 1 to 14; the experimental data are plotted along with the calculated curves. For clarity only some selected isotherms are reported.

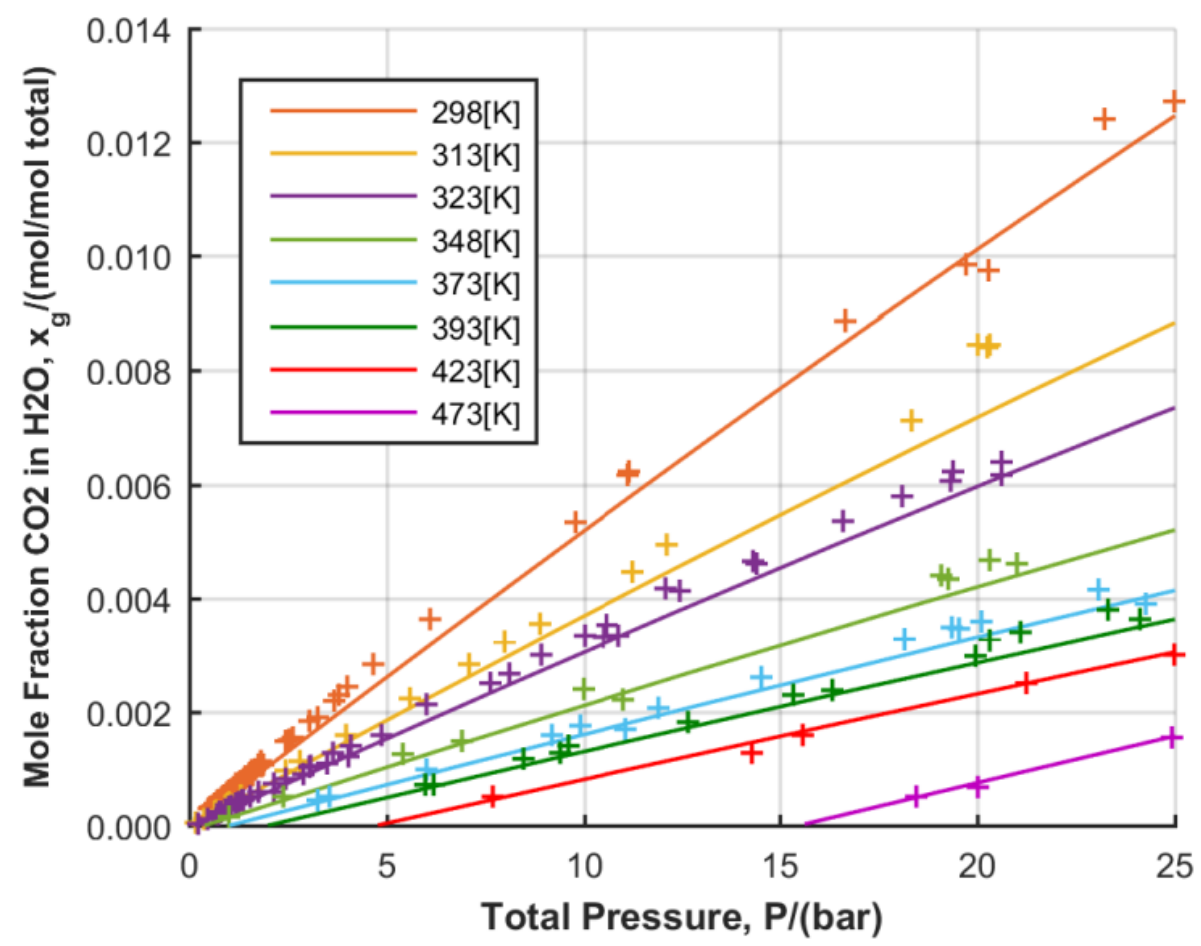

Figure 1: Isothermal pressure and liquid composition data for $\mathrm{CO}_{2}-\mathrm{H}_{2} \mathrm{O}$ system up to 25 bar in the temperature range 298-473 K: $(+)$ experimental data from different sources and (-) model prediction

$\mathrm{CO}_{2}$ solubilities in water at moderate pressures are showed in Figure 1. The experimental data for this system span over a temperature range of more than $300{ }^{\circ} \mathrm{C}$. Two $\left(u_{T 0}, u_{T 1}\right)$ and three constants $\left(h_{1}, h_{2}, h_{3}\right)$, respectively, may not be sufficient to correctly describe temperature trends of the UNIQUAC interaction parameters and the Henry's law constant over such interval. This can explain the underestimation of $\mathrm{CO}_{2}$ solubility at the lowest temperatures, while for temperatures above $323 \mathrm{~K}$ the model predictions seem in good agreement with the corresponding 
experimental points. Indeed, in approximately the same temperature range the vapor pressures of pure water are commonly fitted using 5 coefficients (e.g. the non-zero coefficients reported in Table 5 for the AspenTech extended Antoine equation ${ }^{26}$, or the 5 coefficients adopted for water in DIPPR-101 equation ${ }^{37}$ ).

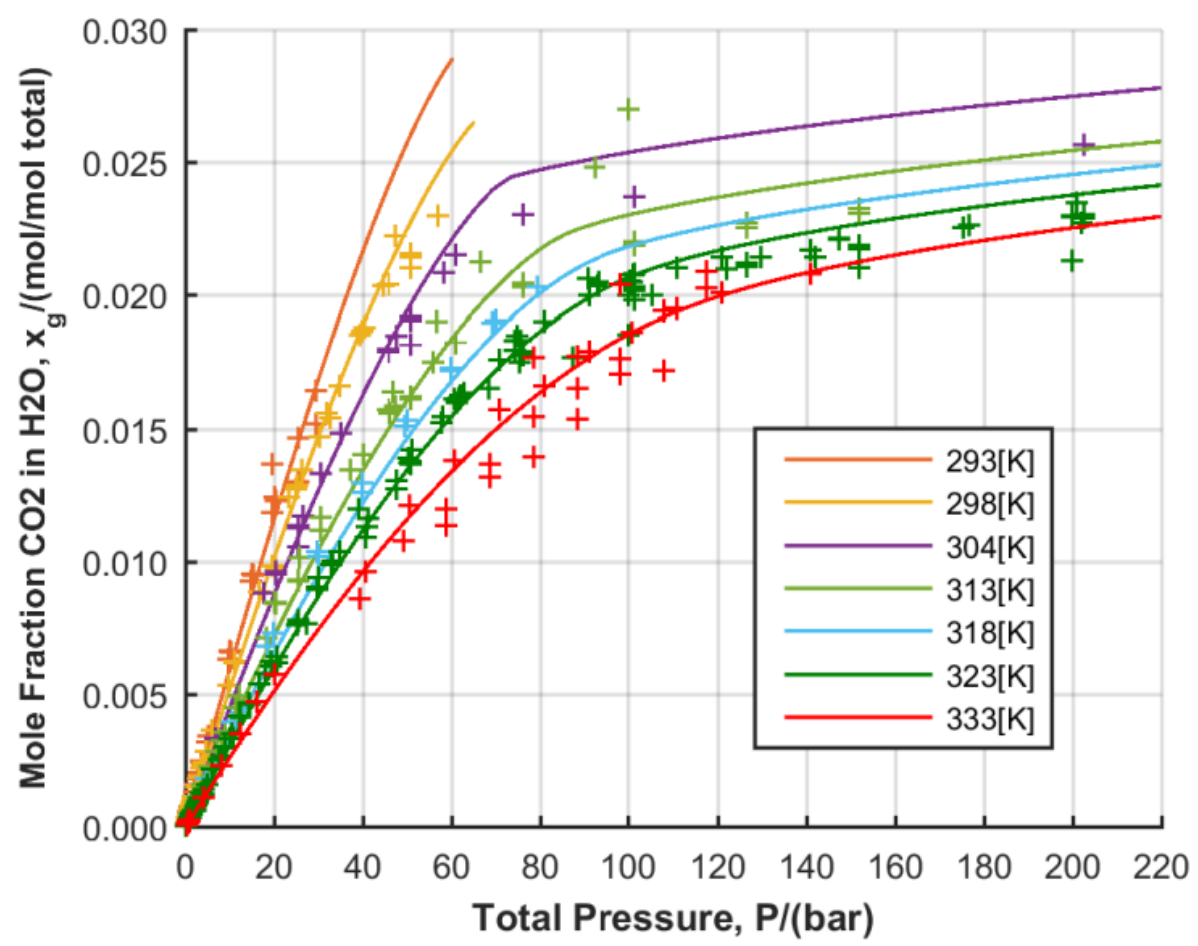

Figure 2: Isothermal pressure and liquid composition data for $\mathrm{CO}_{2}-\mathrm{H}_{2} \mathrm{O}$ system up to 220 bar in the temperature range 293-333 K: $(+)$ experimental data from different sources and (-) model prediction

$\mathrm{CO}_{2}$ solubilities in water for pressure up to 220 bar and temperature up to $333 \mathrm{~K}$ are reported in Figure 2. The two isotherms at $293 \mathrm{~K}$ and $298 \mathrm{~K}$ were plotted only for pressures below the liquid-liquid split $\left({ }^{50},{ }^{51}, 52\right)$. This is done because the model parameters are not intended, and should not be used to represents VLLE or LLE regions, in view of the fact, at these conditions, the second phase (the $\mathrm{CO}_{2}$ rich liquid) is too close to its critical point, and the assumption of pressure independent liquid volumes is not any more realistic. It is still noteworthy that, even if 
no LLE or VLLE data were involved in the parametrization, the coefficients reported in Table 4 for this system, allow for the model to approximatively predict the pressures at which the liquidliquid split occurs and, though only qualitatively, to predict the $\mathrm{CO}_{2}$ rich liquid phase compositions. For all isotherms at pressures below 80 bar, the deviations between the model predictions and the experimental points are mainly due to the scatter in the data. For higher pressure $\mathrm{CO}_{2}$ solubilities are generally over-predicted, but also the experimental points from the different sources differ quite remarkably from each other, e.g. the points at $313 \mathrm{~K}$ between 40 and 100 bar, primarily from ${ }^{53}$ and ${ }^{54}$.

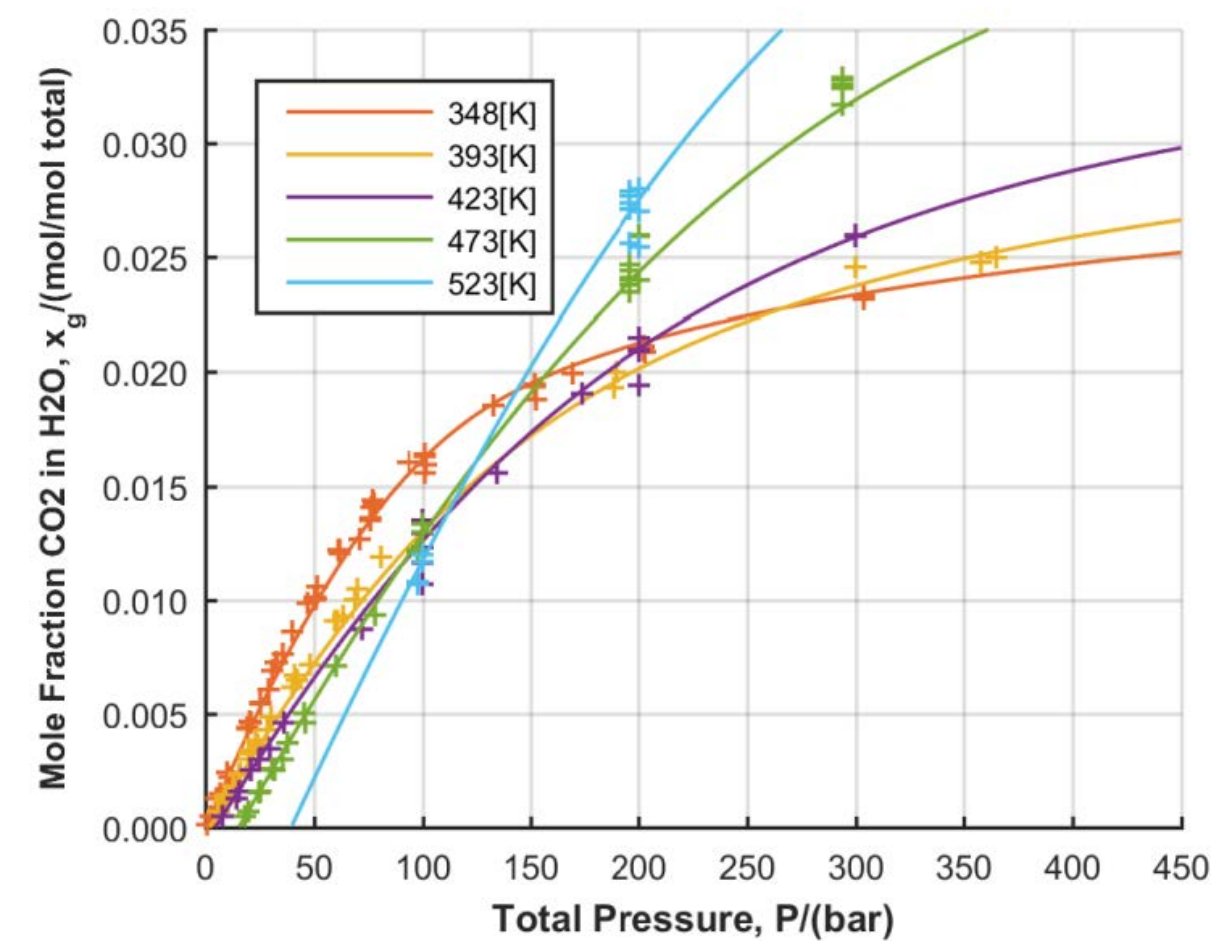

Figure 3: Isothermal pressure and liquid composition data for $\mathrm{CO}_{2}-\mathrm{H}_{2} \mathrm{O}$ system up to 400 bar in the temperature range 348-523 $\mathrm{K}:(+)$ experimental data from different sources and (-) model prediction

Figure 3 shows that, for the temperature range $348 \mathrm{~K}$ and $523 \mathrm{~K}$, model predictions and experimental points concur over the entire pressure interval. With increasing pressure the 
Poynting correction tends to diminish the gas solubility compared to a straight line prediction, however the reason of the sharp change in the slope of the isotherms observed in Figures 2 and 3 at around $80-100$ bar is due to a strong non ideality of $\mathrm{CO}_{2}$ in the vapor phase. Though supercritical above $305 \mathrm{~K}$, for the higher pressures considered in the present study, pure $\mathrm{CO}_{2}$ can still show liquid-like densities and sharp variations in the compressibility factor. The model prediction for the system $\mathrm{CO}_{2}-\mathrm{H}_{2} \mathrm{O}$ agrees well with the experimental data within the temperatures and pressures range of the datasets involved in the regression, Table 1.

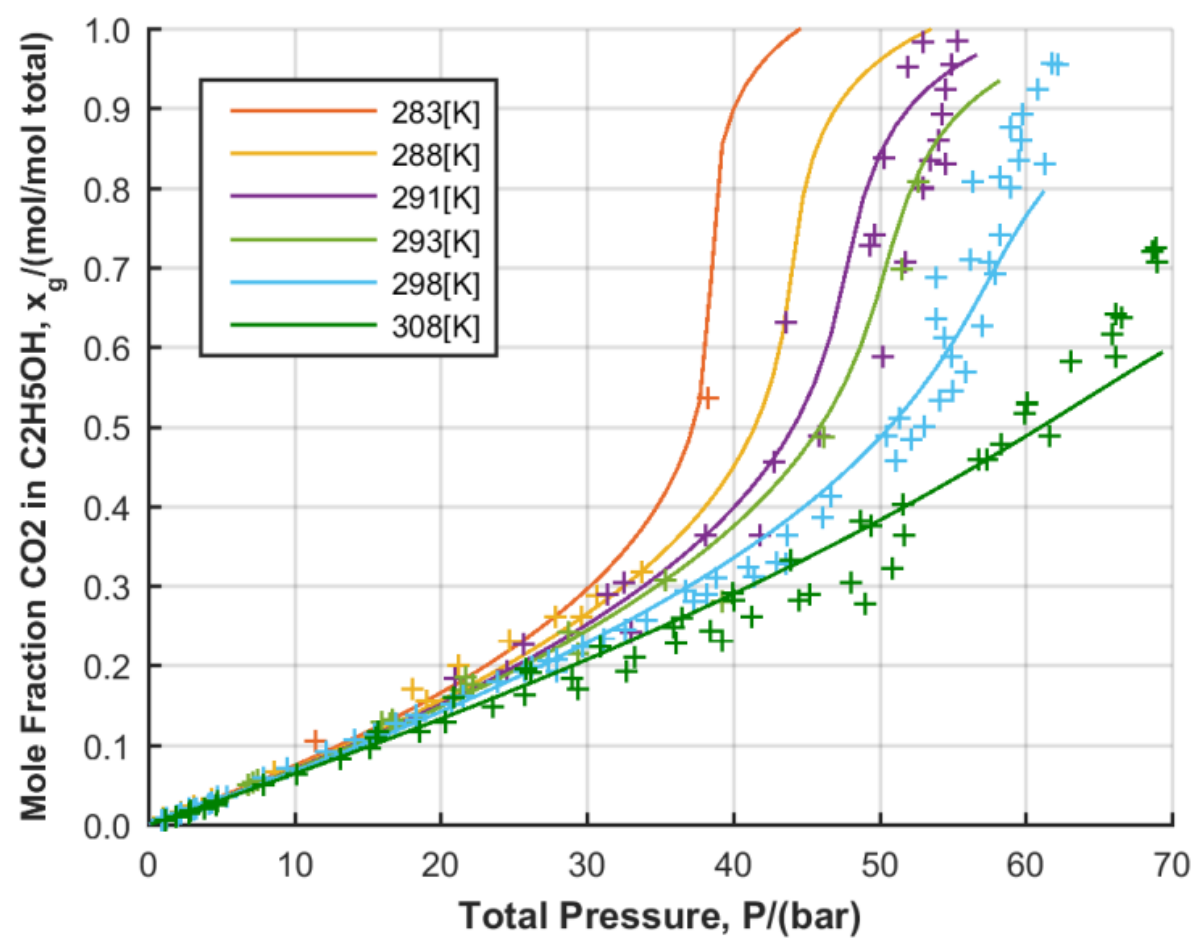

Figure 4: Isothermal pressure and liquid composition data for $\mathrm{CO}_{2}-\mathrm{C}_{2} \mathrm{H}_{5} \mathrm{OH}$ system up to 70 bar in the temperature range 283-308 $\mathrm{K}:(+)$ experimental data from different sources and (-) model prediction 


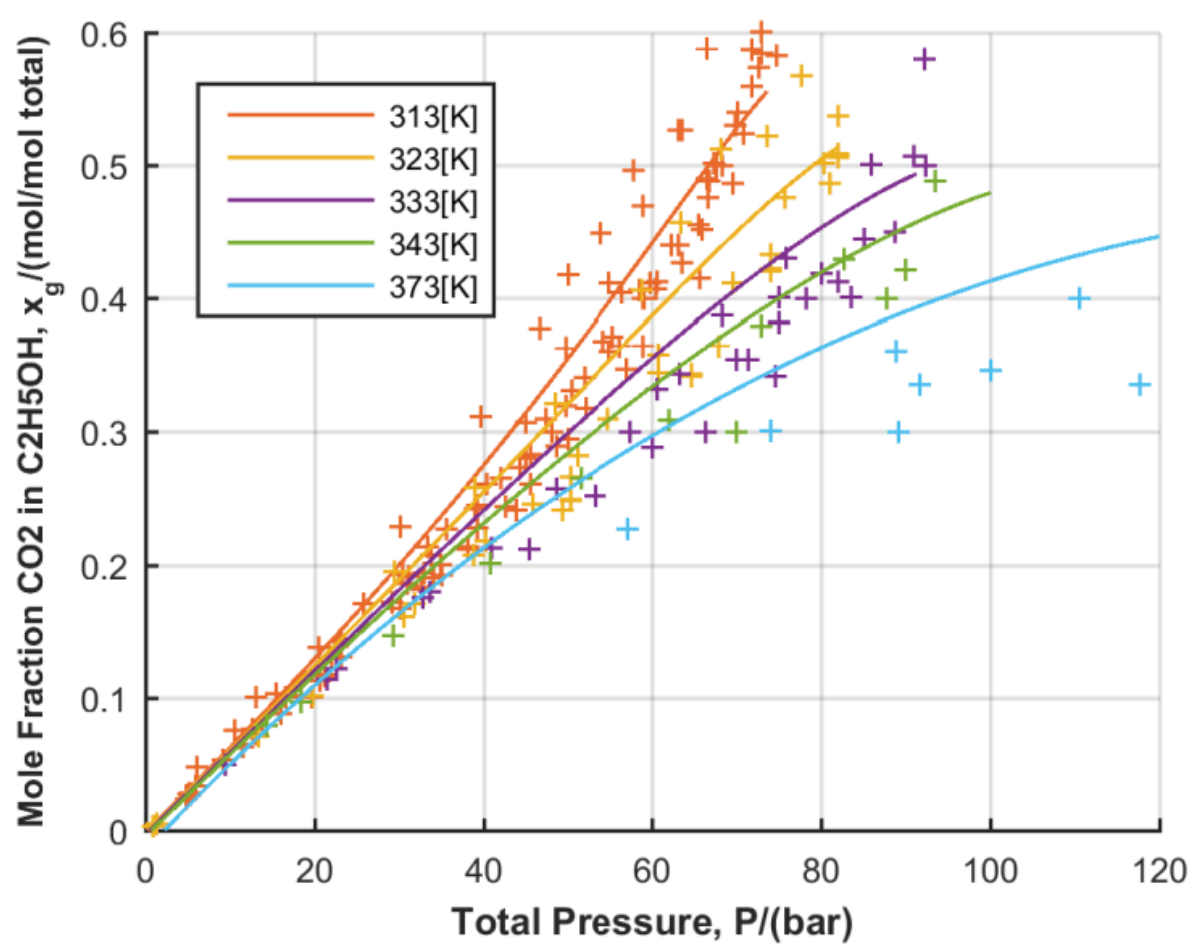

Figure 5: Isothermal pressure and liquid composition data for $\mathrm{CO}_{2}-\mathrm{C}_{2} \mathrm{H}_{5} \mathrm{OH}$ system up to 120 bar in the temperature range 313-373 K: $(+)$ experimental data from different sources and (一) model prediction

$\mathrm{CO}_{2}$ solubilities in ethanol, for pressure up to 70 bar and temperature from 283 to $308 \mathrm{~K}$, are reported in Figure 4. Below $283 \mathrm{~K}$, the model can be used to calculate the phase equilibrium over the entire compositional range. For the other isotherms the critical conditions are progressly reached for smaller amounts of $\mathrm{CO}_{2}$ in the mixture; that's the reason the lines in Figures 4 and 5 are not extend beyond a certain $\mathrm{CO}_{2}$ concertation. $\mathrm{CO}_{2}-\mathrm{C}_{2} \mathrm{H}_{5} \mathrm{OH}$ is also the system that shows the lager deviation between model predictions and experimental data, as can be seen from the corresponding AAD\% value of 12.6\% repotted in Table 1. Figures 4 and 5 give an insight on the possible causes. The scatter of the experimental points around the corresponding isotherms is evidently the main reason for the high $\mathrm{AAD} \%$. Another explanation could be that data too close to the mixture critical conditions were used and therefore not properly modelled in the $\gamma-\varphi$ 
framework. This is especially seen in the two isotherms at $298 \mathrm{~K}$ and $308 \mathrm{~K}$, Figure 4, above 50 bar, where the model seems to indicate a slightly more straight behavior compared to the more concave trend in the data. Within the boundary imposed by the mixture critical conditions and the temperature and pressure ranges reported in Table 1, and despite the poor quality of the data, the behavior of the system $\mathrm{CO}_{2}-\mathrm{C}_{2} \mathrm{H}_{5} \mathrm{OH}$ is adequately reproduced by the model.

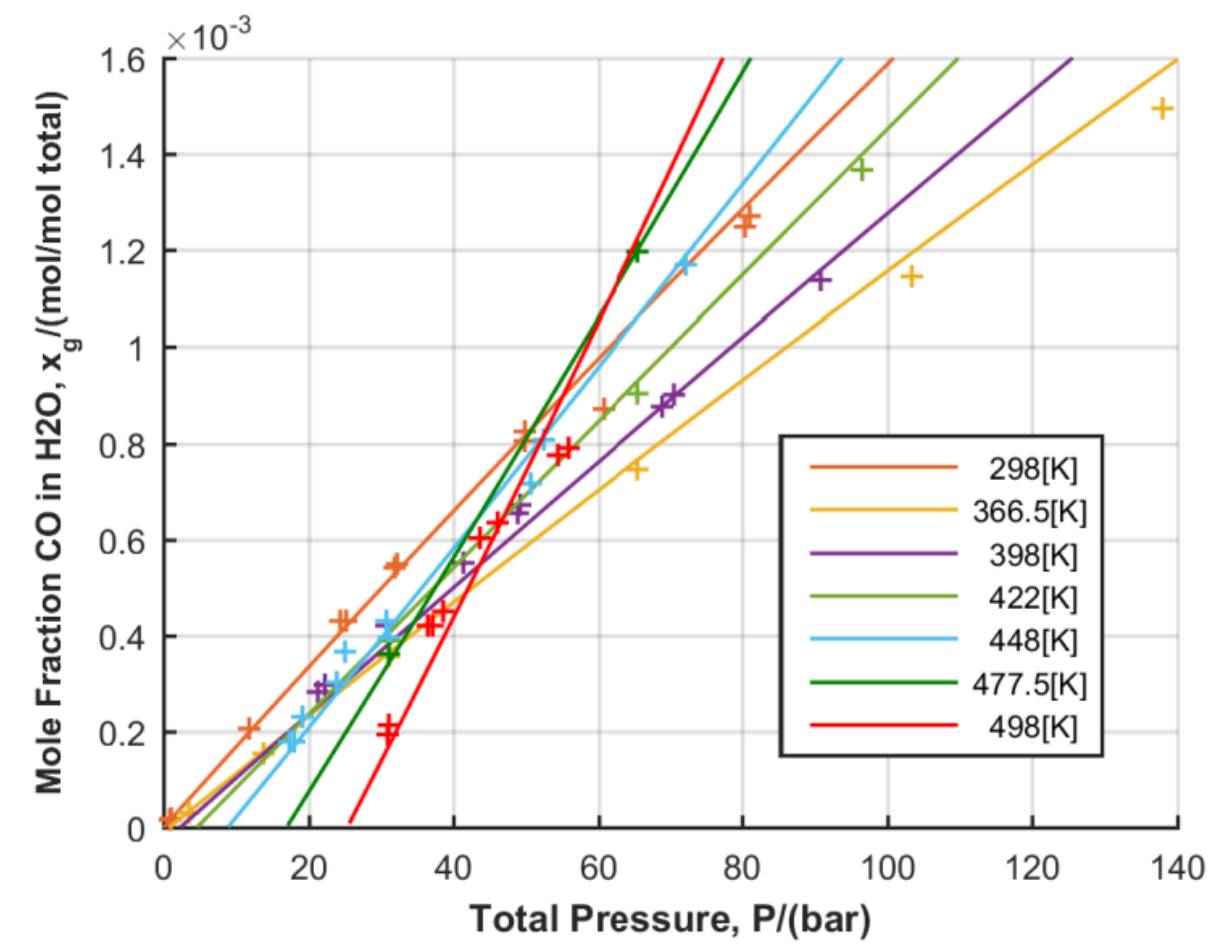

Figure 6: Isothermal pressure and liquid composition data for $\mathrm{CO}-\mathrm{H}_{2} \mathrm{O}$ system up to $140 \mathrm{bar}$ in the temperature range 298-498 K: $(+)$ experimental data from different sources and (一) model prediction

$\mathrm{CO}-\mathrm{H}_{2} \mathrm{O}$ is a reactive system, as the water gas shift reaction (WGS) is thermodynamically favorable. According to Jung and Knacke study ${ }^{55}$, for temperature above $250{ }^{\circ} \mathrm{C}$ the reaction turnover is sufficiently high to affect the chemical composition of the system, even in the absence of an appropriate catalyst. For this reason, CO solubility measurements, conducted at temperatures above $520 \mathrm{~K}$, were not included in the data regression. Figure 6 reports the 
isotherms and the experimental points for $\mathrm{CO}-\mathrm{H}_{2} \mathrm{O}$ system in the temperature range $298 \mathrm{~K}$ to 498 $\mathrm{K}$ and pressures up $140 \mathrm{bar}$. All isotherms show a linear trend, as to be expected from systems of sparingly soluble gases, but at the higher pressures, a slight positive curvature should still be present. This is not the case since the growth of the Pointing term is somehow balanced by a decrease in the solute activity coefficient; i.e. $\gamma_{g}^{*}(T, \mathbf{n}) \exp \left[\bar{v}_{g}^{\infty}\left(P-P_{i}^{\text {sat }}\right) / R T\right] \cong 1$. The model correctly predicts the experimental data over the entire range, Table 1.

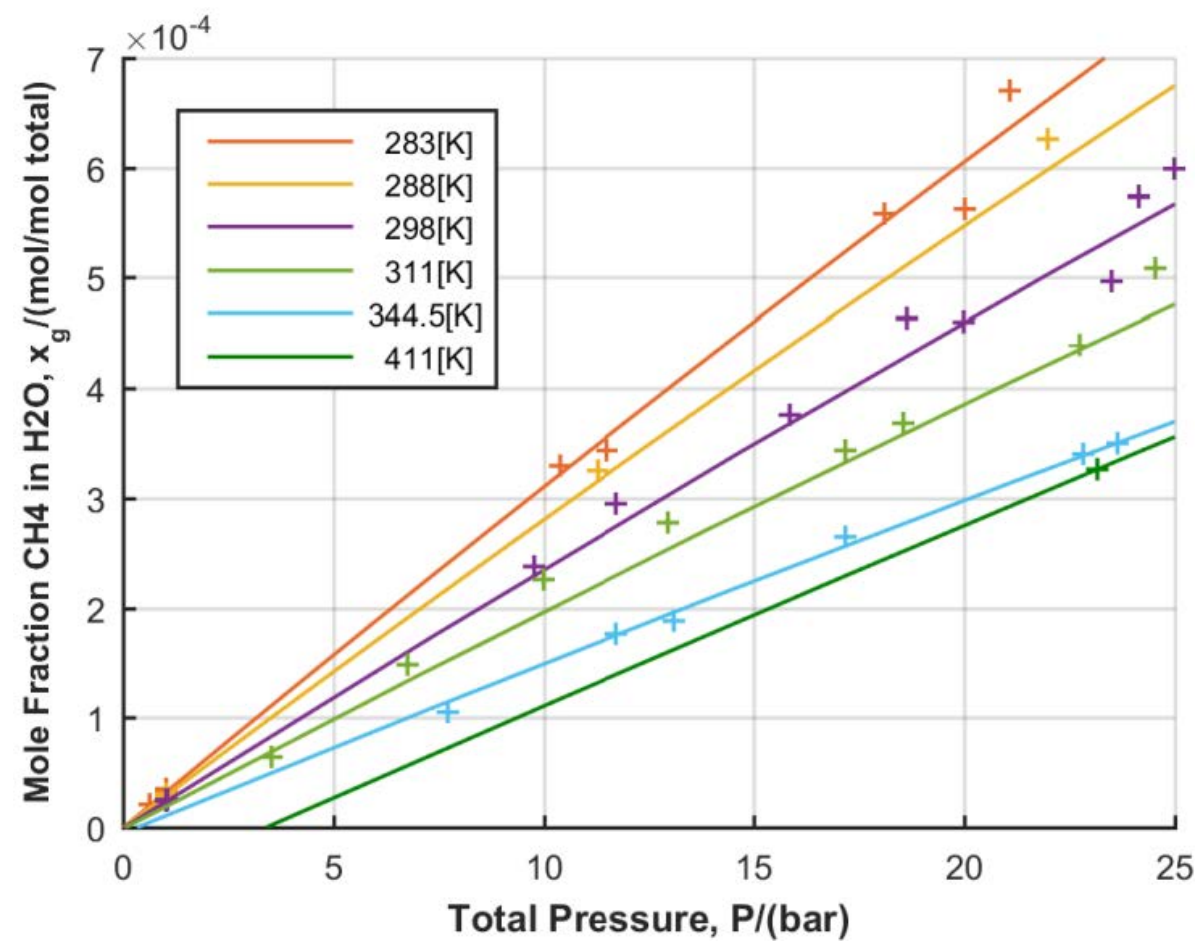

Figure 7: Isothermal pressure and liquid composition data for $\mathrm{CH}_{4}-\mathrm{H}_{2} \mathrm{O}$ system up to 25 bar in the temperature range 283-411 K: $(+)$ experimental data from different sources and (-) model prediction 


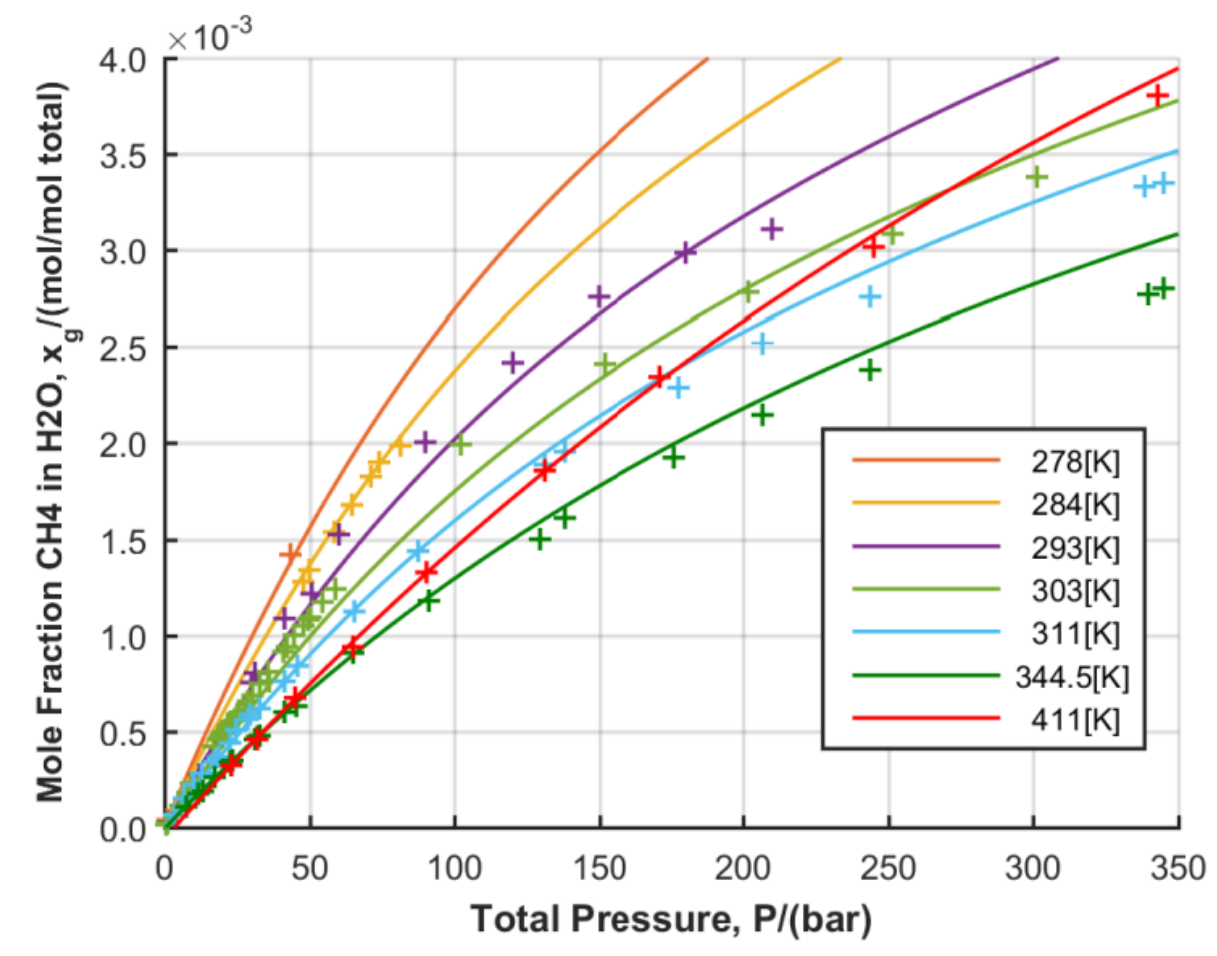

Figure 8: Isothermal pressure and liquid composition data for $\mathrm{CH}_{4}-\mathrm{H}_{2} \mathrm{O}$ system up to 350 bar in the temperature range 278-411 K: $(+)$ experimental data from different sources and (-) model prediction

Figures 7 and 8 and, shows the solubilities of $\mathrm{CH}_{4}$ in water for two ranges of pressure, respectively up to $25 \mathrm{bar}$ and up to 350 bar. At high pressures and for temperatures below $20^{\circ} \mathrm{C}$, the formation of $\mathrm{CH}_{4}-\mathrm{H}_{2} \mathrm{O}$ clathrate crystals may lead to incorrect estimations of $\mathrm{CH}_{4}$ solubility ${ }^{56}$; thus points presenting unusually high $\mathrm{CH}_{4}$ solubilities, clearly non in line with the rest of the experimental data, were discarded in advance. The model correctly predicts the mole fraction of $\mathrm{CH}_{4}$ in water for the entire range of pressure considered in Figure 7, and for the first half of the pressure interval reported in Figure 8. Above 200 bar, gas solubilities seems to be overestimated in particular for the isotherms at $311 \mathrm{~K}$ and $344.5 \mathrm{~K}$. Model predictions are consistent with the trends of the datasets even in the vicinity of the experimental data; e.g. for the isotherms at $553 \mathrm{~K}$ and $565 \mathrm{~K}$ up to 350 bar. 


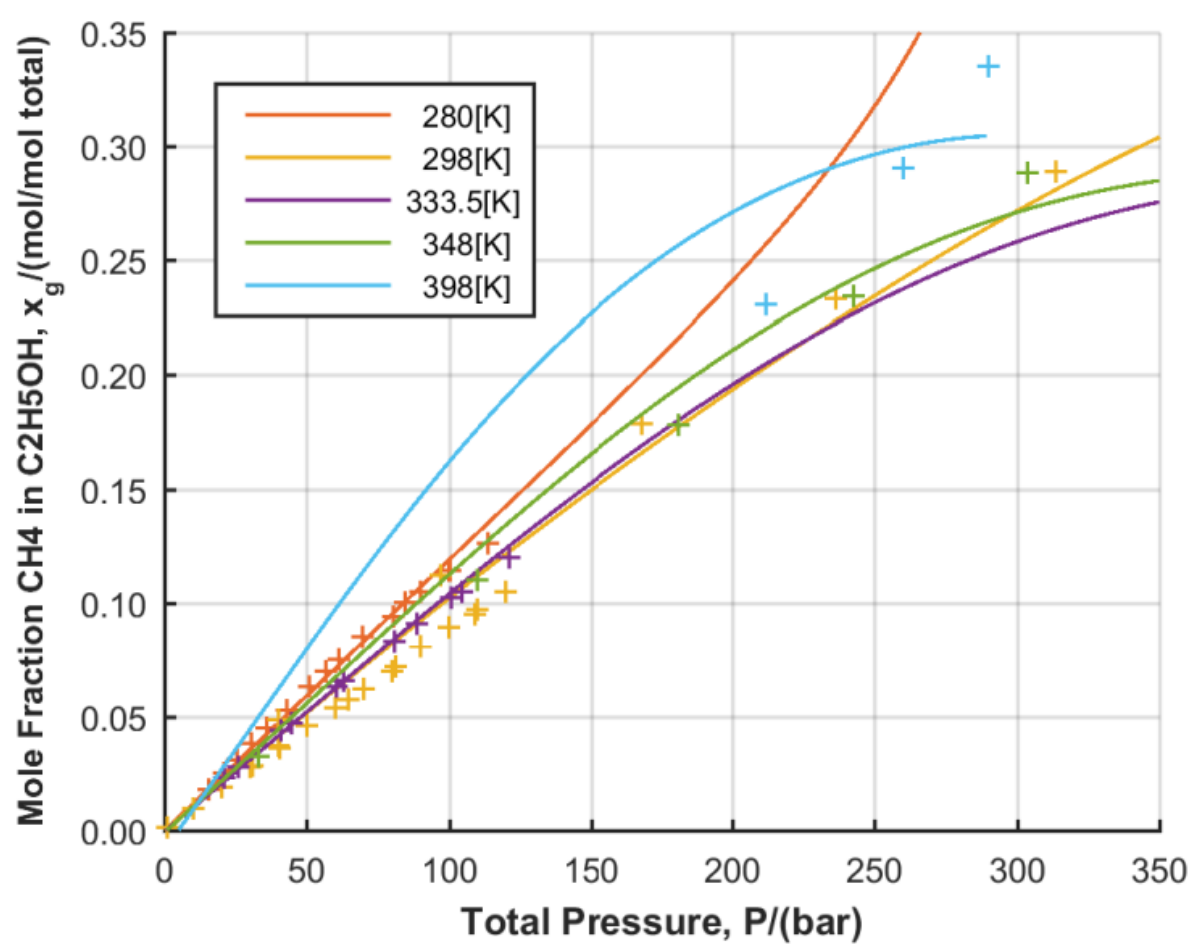

Figure 9: Isothermal pressure and liquid composition data for $\mathrm{CH}_{4}-\mathrm{C}_{2} \mathrm{H}_{5} \mathrm{OH}$ system up to 350 bar in the temperature range 280-398 $\mathrm{K}:(+)$ experimental data from different sources and (-) model prediction

$\mathrm{CH}_{4}-\mathrm{C}_{2} \mathrm{H}_{5} \mathrm{OH}$, in Figure 9, is the system that shows the second larger deviations between experimental points and model predictions, however, the various datasets from the different sources are not always in agreement to each other. This can be appreciated from the isotherm at $298 \mathrm{~K}$, the only sources available for pressures above atmospheric are ${ }^{57}$ and ${ }^{58}$, in the range common to the two studies (up to 120 bar), the first datasets suggests higher solubilities, while the second one shows lower solubilities than the calculated ones. The general trend of the experimental points implies a linear dependence of $\mathrm{CH}_{4}$ solubilities from pressure; while, the isotherms at $348 \mathrm{~K}$ and $398 \mathrm{~K}$, show a clear reduction in $\mathrm{CH}_{4}$ solubilities due to a consistent growth of the Pointing term at higher temperatures. The isotherm at $398 \mathrm{~K}$ cannot be extended further, since for higher $\mathrm{CH}_{4}$ content in the liquid, the mixture closely approaches its critical 
conditions, ${ }^{57}$. For the highest pressure considered in Figure 9, the model predictions show a behavior opposite to that indicated by the experimental points and more similar to that of $\mathrm{CO}_{2}$ $\mathrm{C}_{2} \mathrm{H}_{5} \mathrm{OH}$ system. Aside from the datasets quality, this could be due to an overestimation in the molar volume of $\mathrm{CH}_{4}$ in this solvent, leading to a compensating effect at the expense of the UNIQUAC parameters. In fact, the type of behavior observed in Figure 9 is mainly related to the Poynting correction and the applied molar volumes, since the UNIQUAC model was used without any tuning of $\bar{v}_{g}^{\infty}$. Acceptable prediction can still be obtained for temperatures between $290 \mathrm{~K}$ and $350 \mathrm{~K}$ up to 300 bar.

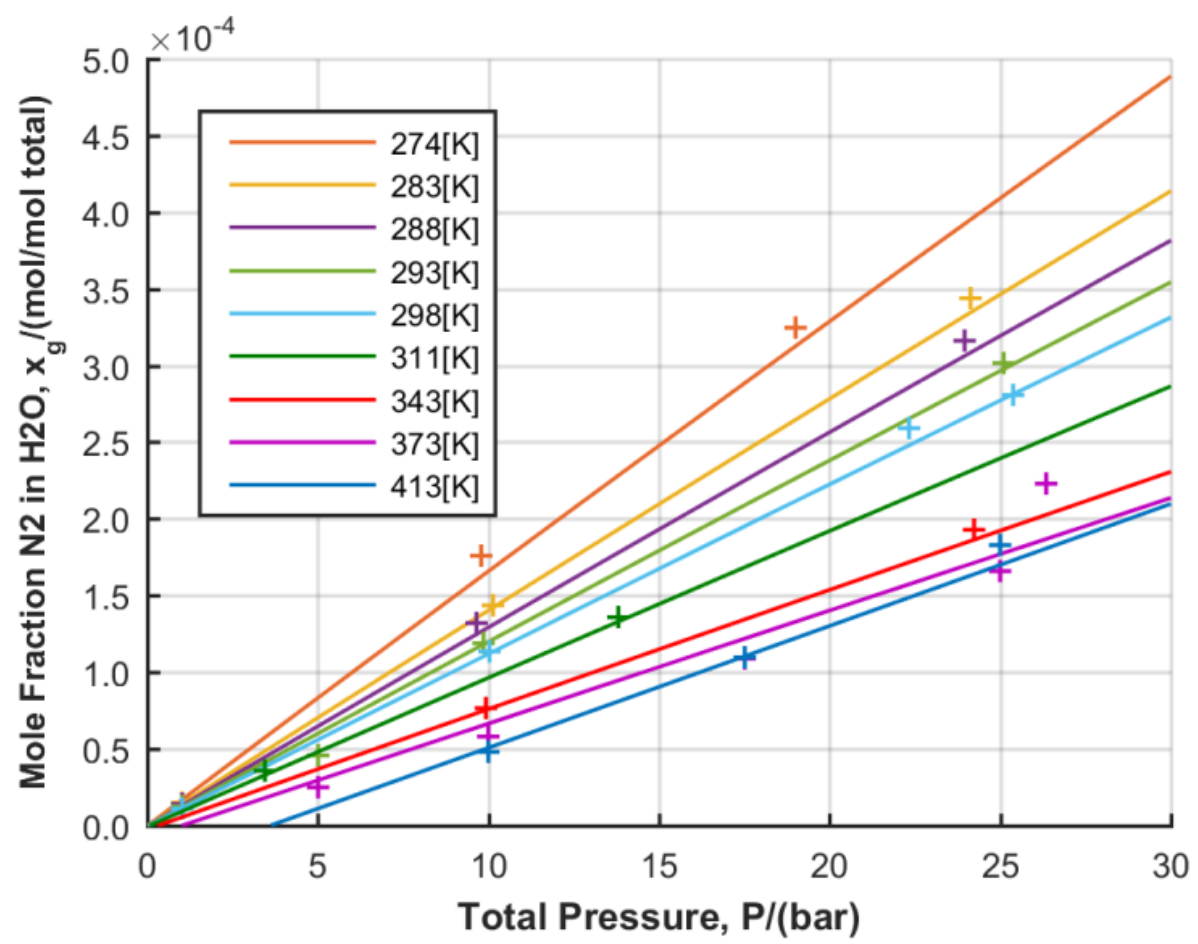

Figure 10: Isothermal pressure and liquid composition data for $\mathrm{N}_{2}-\mathrm{H}_{2} \mathrm{O}$ system up to 30 bar in the temperature range 274-413 $\mathrm{K}:(+)$ experimental data from different sources and (-) model prediction 


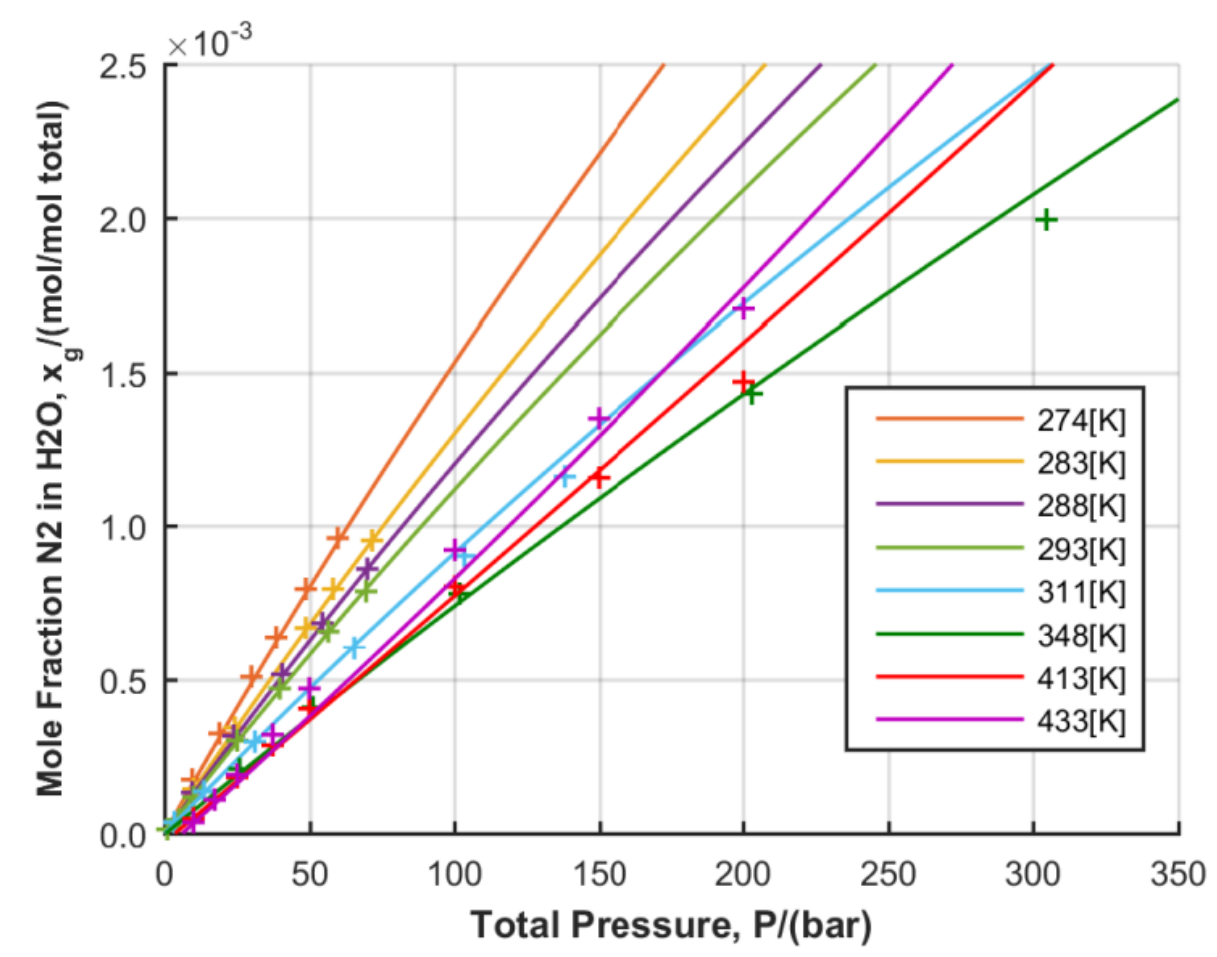

Figure 11: Isothermal pressure and liquid composition data for $\mathrm{N}_{2}-\mathrm{H}_{2} \mathrm{O}$ system up to 350 bar in the temperature range 274-433 K: $(+)$ experimental data from different sources and $(-)$ model prediction

Figures 10 and 11 shows the solubilities of $N_{2}$ in water for two ranges of pressure, respectively up to 30 bar and up to 350 bar. Model prediction and experimental points seems in good agreement, both suggest a linear relationship between solubility and pressure over the entire temperature interval considered, Table 1 . As previously observed for $\mathrm{CO}-\mathrm{H}_{2} \mathrm{O}$ system, Figure 6 , this is the result of the balancing of two competing contributions to the fugacity of the solute: the pressure effect on the chemical potential, represented by the Pointing term, and the non-ideality of the solution, accounted by the activity coefficient. 


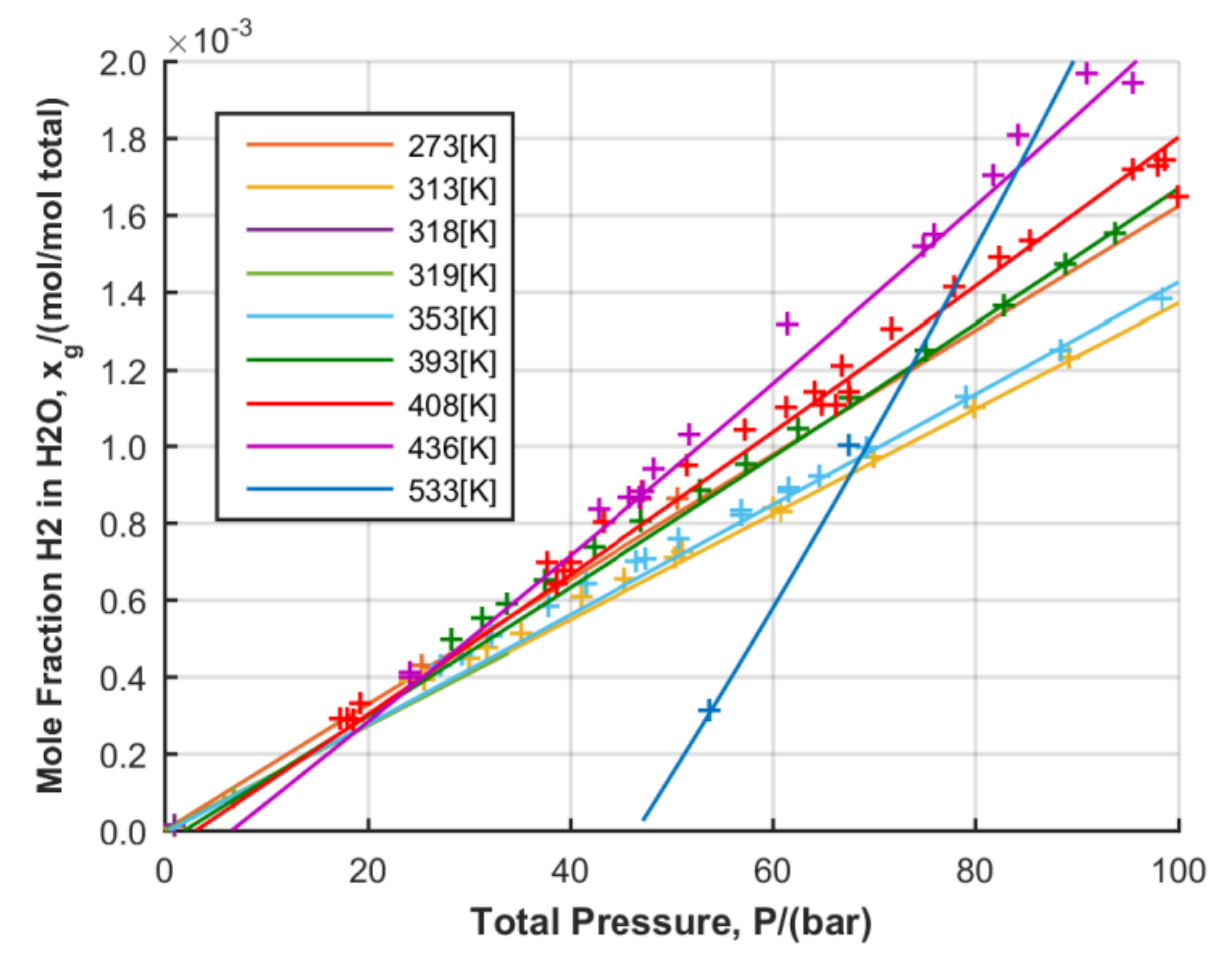

Figure 12: Isothermal pressure and liquid composition data for $\mathrm{H}_{2}-\mathrm{H}_{2} \mathrm{O}$ system up to 100 bar in the temperature range 273-533 K: (+) experimental data from different sources and (-) model prediction

Similarly to $\mathrm{CO}$ and $\mathrm{N}_{2}$ in water, the system $\mathrm{H}_{2}-\mathrm{H}_{2} \mathrm{O}$, in Figures 12 and 13, shows linear dependency of $\mathrm{H}_{2}$ solubilities from pressure, and for the isotherms below $373 \mathrm{~K}$ this behavior is maintained up to 450 bar. Though $\mathrm{H}_{2}$ has the smallest partial molar volume among the gas considered in this study, the Pointing term should visibly affect the curvature of the isotherms, in a sense of reducing the solubilities compared to a straight line prediction, at least for the highest pressures. The fact that the calculated isotherms and the experimental points lie on straight lines, is evidence of a small deviation from the ideal diluted solution behavior even for $\mathrm{H}_{2}$ concertation less than 0.01 mole fraction. It should however be considered that for the higher pressures reported in Figure 13 also the fugacity coefficient for $\mathrm{H}_{2}$ in the vapor phase deviate noticeably from 1 . This is especially true, regardless of pressure, for the isotherm at $575 \mathrm{~K}$. For this system, 
as for $\mathrm{CO}$ and $\mathrm{N}_{2}$ in water, the model predictions are reliable for the entire range of pressures and temperatures considered.

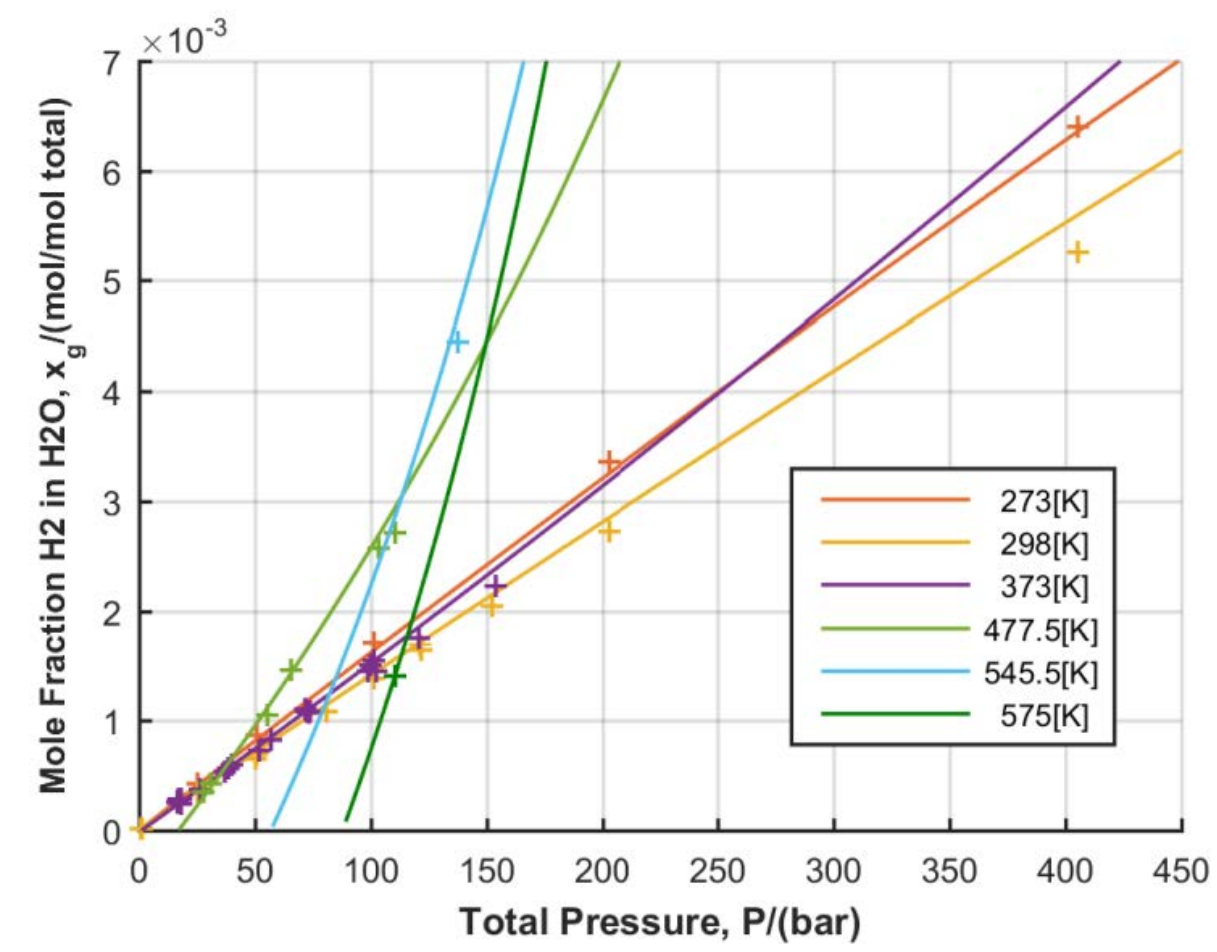

Figure 13: Isothermal pressure and liquid composition data for $\mathrm{H}_{2}-\mathrm{H}_{2} \mathrm{O}$ system up to 450 bar in the temperature range 273-575 K: (+) experimental data from different sources and (-) model prediction

For mixtures containing acetic acid as solvent, the experimental data only cover a relative restrict interval of conditions and generally no more than one datasets for each temperature is available. A low degree of scattering of the data and a limited range of pressure-temperature conditions to be reproduced are the main reasons of the very small deviations observed between model predictions and experimental points. For the same reasons the thermodynamic model accurately fits the experimental points of $\mathrm{CO}-\mathrm{C}_{2} \mathrm{H}_{5} \mathrm{OH}$ and $\mathrm{N}_{2}-\mathrm{C}_{2} \mathrm{H}_{5} \mathrm{OH}$ systems; the respective range of temperatures and pressures covered are reported in Table 1. 


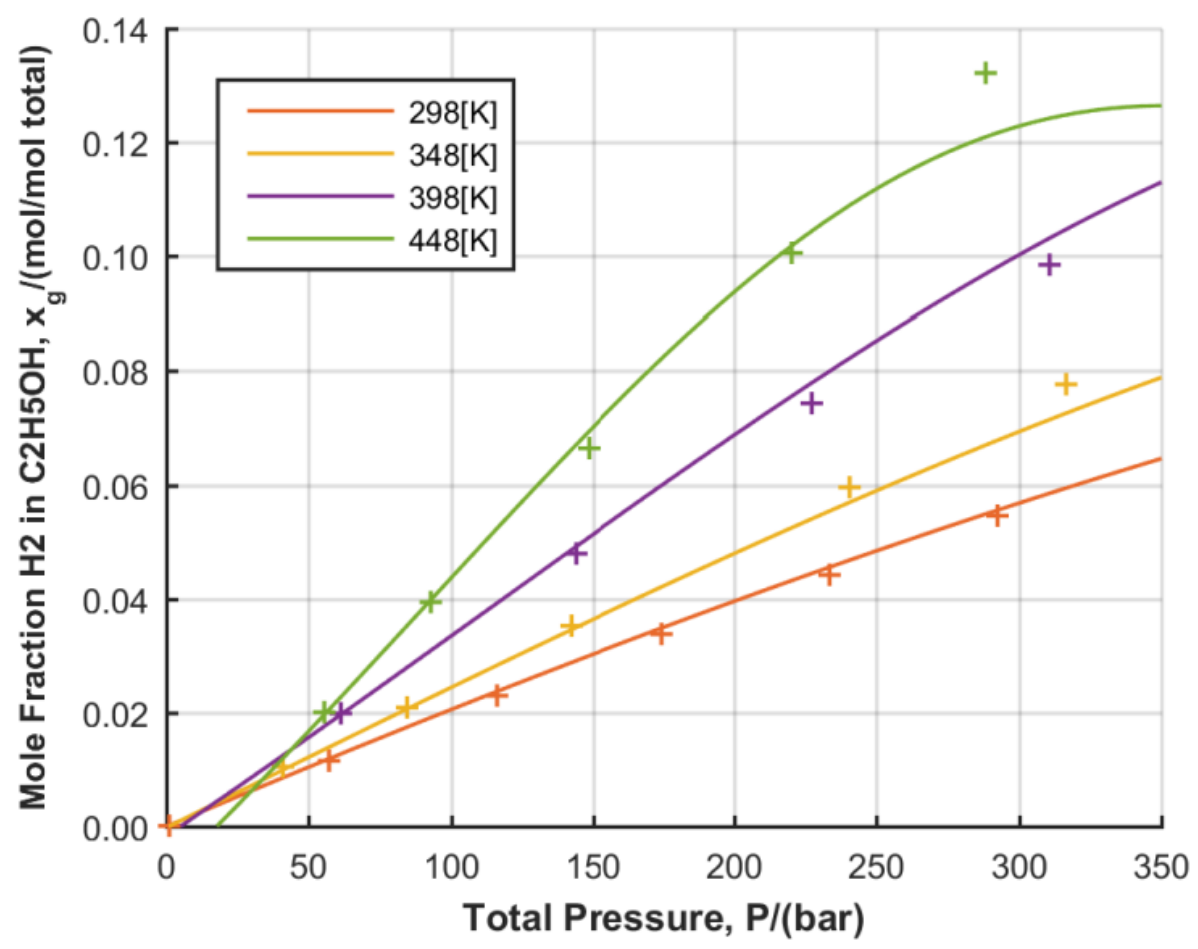

Figure 14: Isothermal pressure and liquid composition data for $\mathrm{H}_{2}-\mathrm{C}_{2} \mathrm{H}_{5} \mathrm{OH}$ system up to 350 bar in the temperature range 298-448 K: $(+)$ experimental data from different sources and (一) model prediction

Figure 14 shows model predictions and experimental points for $\mathrm{H}_{2}$ solubilities in ethanol, the trends of the isotherms and the datasets concur for the entire interval of pressure and temperature presented in the figure. The isotherm at $448 \mathrm{~K}$ displays a consistent decline in the slope with pressure, while the corresponding experimental points seem to suggest a more linear relationship with $\mathrm{H}_{2}$ solubilities. This is probably due to the overestimation of $\bar{v}_{g}^{\infty}$ at the higher temperature as seen in Figure 9 for $\mathrm{CH}_{4}$ solubilities in the same solvent. For temperatures up to $400 \mathrm{~K}$ the model can be safely applied at pressures above 300 bar. For higher temperatures the model predictions should be limited to 250 bar. 


\section{Conclusion}

A $\gamma-\varphi$ phase equilibrium model is presented to describe the phase behavior of 14 gas-solvent systems of relevance for syngas fermentation process and for others industrial applications. The UNIQUAC model has been chosen to calculate the activity coefficients, while the PengRobinson EoS or, for system containing acetic acid, the Hayden-O’Connell Virial EoS were used to calculate the vapor phase fugacities.

A method to estimate gas solubility in mixed solvents based on the thermodynamic relation of the Henry’s law constant with activity coefficient at infinite dilution and the hypothetical liquid standard state fugacity, has been derived. The proposed method only requires the values of the symmetric activity coefficients at infinite dilution and the values of the Henry's law constants in the pure solvents forming the mixture. Therefore, it can be applied to any multi-component system for which the binary pairs of the chosen excess Gibbs energy model are known.

The same thermodynamic relationship has been further exploited in the model parametrization, so as to enforce thermodynamic consistency on the model coefficients. In addition, by expressing the UNIQUAC delta interaction coefficients as difference between interaction parameters and assuming the self-interactions to be the independent of the system, was possible to substantially reduce the number of constants involved in the fitting.

Despite the introduction of thermodynamic constraints, the use of a reduced set of constants for the UNIQUAC equation, and the adoption of a correlation (Brelvi-O'Connell) to estimate the volume of the gas at infinite, only moderate losses in terms of fitting flexibility were observed, as the model can reproduce most of the data within the experimental accuracy. The major deviations between experimental points and model predictions especially occur when inconsistencies between the sources are also evident. 
The results presented show that the model performs very well even at higher temperatures and pressures. Indeed, the $\gamma-\varphi$ framework does not allow a proper description of the system only when applied to describe the fluids close to the mixture critical conditions.

Regarding the modeling of $\mathrm{H}_{2}$ solubility with the UNIQUAC equation, it was noticed that the value given in Bondi ${ }^{34}$ for the Van der Waals radius of the hydrogen atom was too small, and a confirmation of this was found, afterward, in Batsanov work ${ }^{45}$. This shows that, despite the flexibility of the $\gamma-\varphi$ approach, the use of physically incorrect parameters, may significantly compromise the performance of the model, even for those systems that exhibit ideal dilute solution behavior.

\section{Supporting Information Available}

The number of data points involved in the final model parameter estimation and the number of relevant experimental data reported in the original papers are given in the supporting material in conjunction with the corresponding references.

\section{Appendix A}

In this appendix, the equations and the correlation applied for equilibrium computations are presented. These include: 1.The Peng-Robinson EoS ${ }^{35}$ used to calculate the vapor phase fugacities. 2.The Hayden-O'Connell Virial EoS ${ }^{36}$ used to calculate the vapor phase fugacities in the presence of associating species. 3-The DIPPR (Design Institute for Physical Properties) correlations for the estimation of the saturated liquid volumes ${ }^{37}$, for the calculation of the Poynting correction for the solvents. 4-The Brelvi-O’Connell correlation ${ }^{38}$ for the liquid partial molar volume of the supercritical component at infinite dilution conditions, used to evaluate the Poynting correction relative to the solute. 
The relevant thermodynamic properties and correlation coefficients implemented in the computations are listed from Table 1 to Table 6 , in section 5 .

\section{Conversion for the coefficients of Eq. (25)-(26)}

The following relations are used to convert the coefficient of Eq. (25) so that can be employed in the equivalent Eq. (26) for the estimation of the UNIQUAC interaction parameters ${ }^{33}$ as function of temperature.

$$
u_{a}^{\prime}=u_{T 1}-2 u_{T 2} T_{0}-u_{T 3} \ln \left(T_{0}\right) ; \quad u_{b}^{\prime}=u_{T 0}-u_{T 1} T_{0}+u_{T 2}\left(T_{0}\right)^{2} ; \quad u_{c}^{\prime}=u_{T 3} ; \quad u_{d}^{\prime}=u_{T 2}
$$

\section{Peng-Robinson EoS}

Peng-Robinson EoS with the classical mixing rules ${ }^{35}$ is reported below

$$
\begin{aligned}
& P=\frac{R T}{v-b}-\frac{a(T)}{v(v+b)+b(v-b)} ; \quad a(T)=\frac{0.457235\left(R T_{C}\right)^{2}}{P_{C}} \alpha(T) ; \quad b=\frac{0.077796 R T_{C}}{P_{C}} \\
& \alpha(T)=\left[1+\left(0.37464+1.54226 \omega-0.26992 \omega^{2}\right)\left(1-\left(T / T_{C}\right)^{0.5}\right)\right]^{2}
\end{aligned}
$$

$P_{C}, T_{C}$ and $\omega$ are the critical pressure, critical temperature and acentric factor. The classical mixing rules used for the vapor phase are given in Eq. (A4).

$$
a(T, \mathbf{m})=\sum_{i} \sum_{j} x_{i} x_{j}\left(1-k_{i j}\right) \sqrt{a_{i}(T) a_{j}(T)} ; \quad b(\mathbf{m})=\sum_{i} \sum_{j} \frac{x_{i} x_{j}\left(b_{i}+b_{j}\right)}{2}
$$

Here $a_{i}$ and $b_{i}$ are the energy and the co-volume for pure components, $k_{i j}=k_{j i}$ is the binary interaction parameter.

\section{Hayden-O'Connell Virial EoS}

Below is given the Hayden-O'Connell Virial EoS ${ }^{36}$. The method is used for predicting pure and cross second virial coefficients. A parameter to describe chemical association, which 
depends only on the functional group of the molecules, is used in combination with specific mixing rules so to account for solvation effects and association.

Eq. (A5) gives the Virial EoS truncated at the second coefficient and the relative mixing rules; Hayden-O'Connell method calculates the second Virial coefficients for both unlike and selfinteractions as summation of various contributions, Eq. (A6).

$P=\frac{R T}{v}\left(1+\frac{B(T, \mathrm{~m})}{v}\right) ; \quad B(T, \mathrm{~m})=\sum_{i} \sum_{j} y_{i} y_{j} B_{i j}^{t o t}(T)$

$B_{i j}^{\text {tot }}(T)=B_{i j}^{\text {nonpolar }}(T)+B_{i j}^{\text {polar }}(T)+B_{i j}^{\text {metastable }}(T)+B_{i j}^{\text {bound }}(T)+B_{i j}^{\text {chem }}(T)$

Aside from $T_{i C}$ and $P_{i C}$, the additional pure component properties required are the mean radius of gyration $r_{i}^{g y r}$ and the dipole moment $\mu_{i}$. The "nonpolar" acentric factor $\omega^{\prime}{ }_{i i}$, the energy parameter $\varepsilon_{i i}$ and the molecular size parameter $\sigma_{i i}$ are obtained as follows:

$$
\begin{aligned}
& \omega_{i i}^{\prime}=0.006026 r_{i}^{g y r}+0.02096\left(r_{i}^{g y r}\right)^{2}-0.001366\left(r_{i}^{g y r}\right)^{3} \\
& \varepsilon_{i i}^{0}=\left(0.748+0.91 \omega_{i i}^{\prime}-\frac{0.4 \eta_{i i}}{2+20 \omega_{i i}^{\prime}}\right) k_{B} T_{i C} ; \quad \sigma_{i i}^{0}=\left(2.44-\omega_{i i}^{\prime}\right)\left(\frac{T_{i C}}{P_{i C}}\right)^{1 / 3} \\
& \varepsilon_{i i}=\varepsilon_{i i}^{0} ; \quad \sigma_{i i}=\sigma_{i i}^{0} ; \text { for } \mu_{i}<1.45
\end{aligned}
$$$$
\varepsilon_{i i}=\varepsilon_{i i}^{0}-\varepsilon_{i i}^{0} \xi_{i i}\left(\frac{n_{i i}}{n_{i i}-6}\right)\left[1-\frac{\xi_{i i}}{2}\left(\frac{n_{i i}}{n_{i i}-6}+1\right)\right] ; \quad \sigma_{i i}=\sigma_{i i}^{0}\left(1+\frac{3 \xi_{i i}}{n_{i i}-6}\right)^{1 / 3} ; \quad n_{i i}=16+400 \omega_{i i}^{\prime} ; \quad \text { for } \mu_{i}>1.45
$$

$$
\xi_{i i}=\frac{1.7941 \cdot 10^{7} k_{B} \mu_{i}^{4}}{T_{i C}\left(2.882-\frac{1.882 \omega_{i i}^{\prime}}{0.03+\omega_{i i}^{\prime}}\right) \varepsilon_{i i}^{0}\left(\sigma_{i i}^{0}\right)^{6}}
$$

In Eq. (A7)-(A11) the mean radius of gyration should be expressed in $\AA$, the dipole moment in $\mathrm{D}$, the critical pressure in atm, and Boltzmann constant in erg/K $\left(1.3805 \cdot 10^{-16} \mathrm{erg} / \mathrm{K}\right)$. The 
energy parameter and the size parameter will be respectively given in erg and $\AA$. $\eta_{i i}$ is the association parameter for pure interactions.

The cross-coefficients for unlike interactions $\varepsilon_{i j}$, $\sigma_{i j}$, and $\omega_{i j}^{\prime}$ are given by Eq. (A12)-(A16).

$$
\begin{aligned}
& \omega_{i j}^{1}=0.5\left(\omega_{i i}^{\prime}+\omega_{i j}^{\prime}\right) \\
& \varepsilon_{i j}^{0}=0.6\left(\frac{\varepsilon_{i j} \varepsilon_{i j}}{\varepsilon_{i j}+\varepsilon_{i i j}}\right)+0.7\left(\varepsilon_{i i} \varepsilon_{i j}\right)^{1 / 2} ; \quad \sigma_{i j}^{0}=\left(\sigma_{i i} \sigma_{i j}\right)^{1 / 2} \\
& \varepsilon_{i j}=\varepsilon_{i j}^{0} ; \quad \sigma_{i j}=\sigma_{i j}^{0} ; \quad \text { for } \mu_{i} \neq 0 \& \mu_{j} \neq 0 \\
& \varepsilon_{i j}=\varepsilon_{i j}^{0}+\varepsilon_{i j}^{0} \xi_{i j}\left(\frac{n_{i j}}{n_{i j}-6}\right) ; \quad \sigma_{i j}=\sigma_{i j}^{0}\left(1-\frac{3 \xi_{i j}}{n_{i j}-6}\right)^{1 / 3} ; \quad n_{i j}=16+400 \omega_{i j}^{1} \quad \mu_{i}=0 \_o r_{-} \mu_{j}=0 \\
& \xi_{i j}=\frac{k_{B}^{1 / 3} \mu_{i}^{2} \varepsilon_{i j}^{2 / 3} \sigma_{i j}^{4}}{\varepsilon_{i j}^{0}\left(\sigma_{i j}^{0}\right)^{6}} ; \text { for } \mu_{i}>2 \& \mu_{j}=0 ; \quad \xi_{i j}=\frac{k_{B}^{1 / 3} \mu_{j}^{2} \varepsilon_{i j}^{2 / 3} \sigma_{i j}^{4} ; \quad \text { for } \mu_{i}=0 \& \mu_{j}>0}{\varepsilon_{i j}^{0}\left(\sigma_{i j}^{0}\right)^{6}}
\end{aligned}
$$

The contributions to $B_{i j}^{\text {tot }}$, in $\mathrm{cm}^{3} / \mathrm{mole}$, are calculated through Eq. (A19)-(A24). An additional coefficient is required, $\eta_{i j}$ the solvation parameter for unlike interactions. A list for $\eta_{i i}$ and $\eta_{i j}$ can be found in ${ }^{44}$.

$$
\begin{aligned}
& B_{i j}^{0}=1.26184 \sigma_{i j}^{3} ; \quad T_{i j}^{*}=\frac{k_{B} T}{\varepsilon_{i j}} ; \quad \mu_{i j}^{* 0}=\frac{7243.8 k_{B} \mu_{i} \mu_{j}}{\varepsilon_{i j} \sigma_{i j}^{3}} \\
& \mu_{i j}^{*}=\mu_{i j}^{* 0} ; \quad \text { for } \mu_{i j}^{* 0}<0.04 ; \quad \mu_{i j}^{*}=0 ; \quad \text { for } 0.04<\mu_{i j}^{* 0}<0.25 ; \quad \mu_{i j}^{*}=\mu_{i j}^{*_{0}}-0.25 ; \quad \text { for } \mu_{i j}^{* 0}>0.25 \\
& B_{i j}^{\text {nonpolar }}(T)=B_{i j}^{0}\left[0.94-1.47\left(\frac{1}{T_{i j}^{*}}-1.6 \omega_{i j}^{\prime}\right)-0.85\left(\frac{1}{T_{i j}^{*}}-1.6 \omega_{i j}^{\prime}\right)^{2}-1.015\left(\frac{1}{T_{i j}^{*}}-1.6 \omega_{i j}^{\prime}\right)^{3}\right] \\
& B_{i j}^{\text {polar }}(T)=-B_{i j}^{0} \mu_{i j}^{*}\left[0.74-3.0\left(\frac{1}{T_{i j}^{*}}-1.6 \omega_{i j}^{\prime}\right)+2.1\left(\frac{1}{T_{i j}^{*}}-1.6 \omega_{i j}^{\prime}\right)^{2}+2.1\left(\frac{1}{T_{i j}^{*}}-1.6 \omega_{i j}^{\prime}\right)^{3}\right]
\end{aligned}
$$




$$
\begin{aligned}
& B_{i j}^{\text {metastable }}(T)+B_{i j}^{\text {bound }}(T)=-B_{i j}^{0}\left(0.3+0.05 \mu_{i j}^{*}\right) \exp \left(\frac{1.99+0.2\left(\mu_{i j}^{*}\right)^{2}}{T_{i j}^{*}}\right) ; \quad \text { for } \eta_{i j}<4.5 \\
& B_{i j}^{\text {chem }}(T)=B_{i j}^{0}\left[1-\exp \left(\frac{1500 \eta_{i j}}{\left(\varepsilon_{i j} / k_{B}\right) T_{i j}^{*}}\right)\right] \exp \left(\frac{650 \eta_{i j}}{\left(\varepsilon_{i j} / k_{B}\right)+300}-4.27 \eta_{i j}\right) ; \quad \text { for } \eta_{i j}<4.5
\end{aligned}
$$

When compounds with strong association are present in the mixture, $\eta_{i i} \geq 4.5$ and/or $\eta_{i j} \geq$ 4.5, the corresponding interactions are treated according to the chemical theory of dimerization.

$$
\begin{aligned}
& B_{i j}^{\text {metastable }}(T, P)+B_{i j}^{\text {bound }}(T, P)+B_{i j}^{\text {chem }}(T, P)=-\left(\frac{K_{i j}(T)}{2}\right) \frac{R T}{P} ; \text { for } \eta_{i j} \geq 4.5 \\
& B_{i i}^{\text {metastable }}(T, P)+B_{i i}^{\text {bound }}(T, P)+B_{i i}^{\text {chem }}(T, P)=-K_{i i}(T) \frac{R T}{P} ; \quad \text { for } \eta_{i i} \geq 4.5
\end{aligned}
$$

\section{DIPPR-105 and DIPPR-116 correlations for saturated liquid volume}

The two correlations of relevance for the estimation of the saturated liquid volumes, developed by the Design Institute for Physical Properties as part of the DIPPR Project $801^{37}$, are reported below.

$$
\begin{aligned}
& \operatorname{DIPPR}-105 \quad v_{i}^{L} / \mathrm{cc} \cdot \mathrm{mol}^{-1}=\frac{I_{2}^{1+\left(1-\frac{T}{I_{3}}\right)^{4_{4}}}}{I_{1}} \\
& \operatorname{DIPPR}-116 \quad v_{i}^{L} / \mathrm{cc} \cdot \mathrm{mol}^{-1}=\frac{1}{I_{1}+I_{2} \tau^{0.35}+I_{3} \tau^{2 / 3}+I_{4} \tau+I_{5} \tau^{4 / 3}} ; \quad \tau=1-\frac{T}{T_{C}}
\end{aligned}
$$

The correlation parameters give the saturated liquid volume in $\mathrm{cm}^{3} \mathrm{~mol}^{-1}$ when the temperature is expressed in $\mathrm{K}$. 


\section{Brelvi-O'Connell correlation for gaseous solute volume at infinite dilution}

The Brelvi-O’Connell correlation ${ }^{38}$, below presented, can used to estimate the gaseous solute volume at infinite dilution. The equations are formulated in terms of reduced properties and relate the compressibility to the reduced density and the partial molar volume to reduced solvent density.

$$
\begin{aligned}
& \ln \left[\left(\frac{\bar{v}_{g}^{\infty}}{\beta_{i} R T}-1\right)\left(\frac{v_{C i}^{\prime}}{v_{C g}^{\prime}}\right)^{0.62}\right]=-2.4467+2.12074\left(\frac{v_{C i}^{\prime}}{v_{i}^{L}}\right) ; \quad \text { for } 2.0<\left(v_{C i}^{\prime} / v_{i}^{L}\right)<2.785 \\
& \ln \left[\left(\frac{\bar{v}_{g}^{\infty}}{\beta_{i} R T}-1\right)\left(\frac{v_{C i}^{\prime}}{v_{C g}^{\prime}}\right)^{0.62}\right]=3.02214-1.87085\left(\frac{v_{C i}^{\prime}}{v_{i}^{L}}\right)+0.71955\left(\frac{v_{C i}^{\prime}}{v_{i}^{L}}\right)^{2} ; \text { for } 2.785<\left(v_{C i}^{\prime} / v_{i}^{L}\right)<3.2
\end{aligned}
$$

$$
\ln \left(1+\frac{v^{L}}{\beta R T}\right)=-0.42704\left(\frac{v_{C}^{\prime}}{v^{L}}-1\right)+2.0890\left(\frac{v_{C}^{\prime}}{v^{L}}-1\right)^{2}-0.42367\left(\frac{v_{C}^{\prime}}{v^{L}}-1\right)^{3}
$$

In Eq. (A27)-(A28) $\beta_{i}$ is the isothermal compressibility of the solvent, $v_{C i}^{\prime}$ and $v_{C g}^{\prime}$ are the characteristic volumes for the solvent and for the solute; for nonpolar species the characteristic volume can be taken equal to the critical volume, but for polar species this property tends to be smaller.

Eq. (A29) is written for a generic component, it can be fitted to liquid compressibility data to obtain the respective characteristic volume $v_{C}^{\prime}$. When used to calculate $\bar{v}_{g}^{\infty}$, it provides the solvent isothermal compressibility, $\beta_{i}$, required in Eq. (A27)-(A28).

\section{Brelvi-O'Connell isothermal equation of state for liquid densities}

The equation reported below is the integral form of Eq. (A29) as derived in Brelvi and O’Connell ${ }^{59}$, and it can be used to obtain $v_{C}^{\prime}$ from density data only. $\rho_{R}^{*}$ is a scaled density, where the scaling factor is the characteristic volume of the substance. Once the integral of the 
reduced isothermal equation is tabulated, the required values at $\left.\rho_{R}^{*}\right|_{P_{1}}$ and $\left.\rho_{R}^{*}\right|_{P_{2}}$ can be obtained by interpolation.

$$
\frac{v_{C}^{\prime}\left(P_{2}-P_{1}\right)}{R T}=\int_{\left.\rho_{R}^{*}\right|_{\rho_{1}}}^{\left.\rho_{R}^{*}\right|_{2}}\left(\exp \left[-0.42704\left(\rho_{R}^{*}-1\right)+2.0890\left(\rho_{R}^{*}-1\right)^{2}-0.42367\left(\rho_{R}^{*}-1\right)^{3}\right]-1\right) d \rho_{R}^{*} ; \quad \rho_{R}^{*}=\frac{v_{C}^{\prime}}{v^{L}}
$$




\section{Notation}

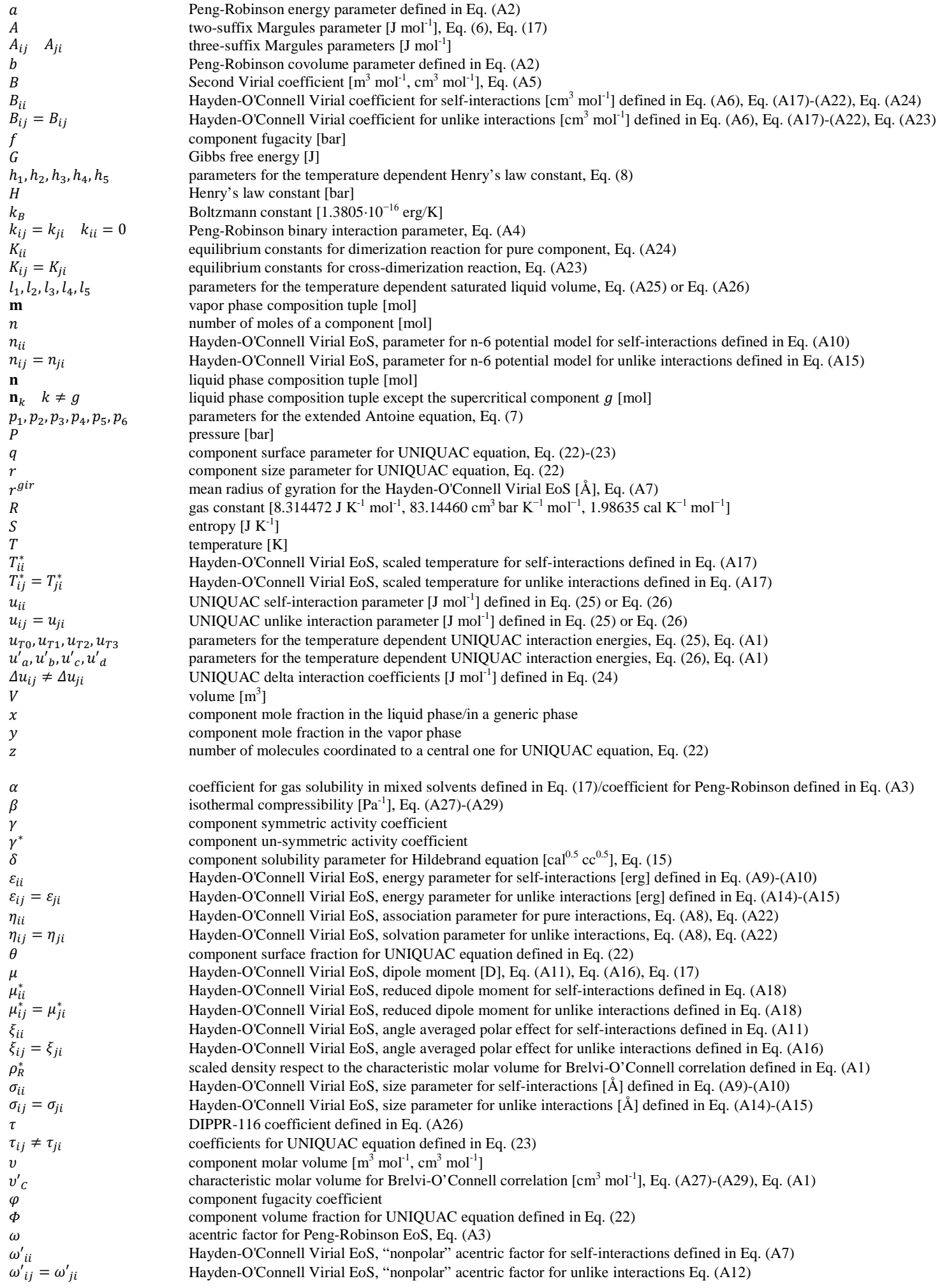




\section{Subscripts}

$\begin{array}{ll}C & \text { critic property } \\ g & \text { supercritical component } \\ i & \text { generic component/pure solvent/solvent forming a mixture } \\ j & \text { generic component/pure solvent/solvent forming a mixture } \\ k & \text { generic component/data point index } \\ R & \text { reduced property } \\ \text { sol } & \text { single solvent system or mixed solvent system } \\ \mathrm{z} & \text { binary system index } \\ 0 & \text { reference temperature }\end{array}$

\section{Superscripts}

bound
calc
chem
corr
C
exp
E
hyp
nonpolar
polar
$R$
sat
tot
$V$
0
$\infty$

\section{Accents}

$\wedge \quad$ mixture property

partial property calculated value

excess property

vapor phase contribution to Hayden-O'Connell Virial coefficient due to physically bound molecule pair

contribution to Hayden-O'Connell Virial coefficient due to chemically bound molecule pair value from Prausnitz and Shair correlation

UNIQUAC combinatorial contribution to the activity coefficient

experimental value

hypothetical liquid standard state

contribution to Hayden-O'Connell Virial coefficient due to non-polar forces for pair interaction

contribution to Hayden-O'Connell Virial coefficient due to polar forces for pair interaction

UNIQUAC residual contribution to the activity coefficient

pure solvent saturation condition/mixed solvents saturation condition

net contribution to Hayden-O'Connell Virial coefficient for pair interaction

Hayden-O'Connell Virial EoS transitory variable

infinitely dilute liquid solution condition 


\section{AUTHOR INFORMATION}

\section{Corresponding Author}

*Philip L. Fosbøl, E-mail: plf@kt.dtu.dk

\section{ACKNOWLEDGMENT}

The authors acknowledge the financial support from the Technical University of Denmark and Innovation Fund Denmark in connection with the SYNFERON project.

\section{REFERENCES}

(1) Higman, C. GSTC Syngas Database: 2017 Update http://worldctx.com/wpcontent/uploads/HigmanGSTC2017.pdf (accessed Feb 13, 2018).

(2) Daniell, J.; Köpke, M.; Simpson, S. D. Commercial Biomass Syngas Fermentation. Energies 2012, 5 (12), 5372-5417.

(3) Bredwell, M. D.; Srivastava, P.; Worden, R. M. Reactor Design Issues for Synthesis-Gas Fermentations. Biotechnol. Prog. 1999, 15 (5), 834-844.

(4) Prausnitz, J. M.; Lichtenthaler, R. N.; de Azevedo, E. G. Molecular Thermodynamics of Fluid-Phase Equilibria, third.; Prentice Hall: New Jersey, 1998.

(5) Carroll, J. J.; Mather, A. E. The System Carbon Dioxide-Water and the KrichevskyKasarnovsky Equation. J. Solution Chem. 1992, 21 (7), 607-621.

(6) Margules, M. Über Die Zusammensetzung Der Gesättigten Dämpfe von Mischungen. Sitzungsberichte der Kais. Akadamie der Wissenschaften Wien Math. Klasse II 1895, 104, $1243-1278$. 
(7) Duan, Z.; Sun, R. An Improved Model Calculating CO2 Solubility in Pure Water and Aqueous $\mathrm{NaCl}$ Solutions from 273 to $533 \mathrm{~K}$ and from 0 to 2000 Bar. Chem. Geol. 2003, 193 (3-4), 257-271.

(8) Pitzer, K. S. Thermodynamics of Electrolytes. I. Theoretical Basis and General Equations. J. Phys. Chem. 1973, 77, 268-277.

(9) Huron, M.-J.; Vidal, J. New Mixing Rules in Simple Equations of State for. Fluid Phase Equilib. 1979, 3 (4), 255-271.

(10) Pedersen, K. S.; Milter, J.; Rasmussen, C. P. Mutual Solubility of Water and a Reservoir Fluid at High Temperatures and Pressures. Fluid Phase Equilib. 2001, 189, 85-97.

(11) Kontogeorgis, G. M.; Voutsas, E. C.; Yakoumis, I. V.; Tassios, D. P. An Equation of State for Associating Fluids. Ind. Eng. Chem. Res. 1996, 35 (11), 4310-4318.

(12) Chapman, W. G.; Gubbins, K. E.; Jackson, G.; Radosz, M. SAFT: Equation-of-State Solution Model for Associating Fluids. Fluid Phase Equilib. 1989, 52, 31-38.

(13) Kontogeorgis, G. M.; Michelsen, M. L.; Folas, G. K.; Derawi, S.; Von Solms, N.; Stenby, E. H. Ten Years with the CPA (Cubic-Plus-Association) Equation of State. Part 2. CrossAssociating and Multicomponent Systems. Ind. Eng. Chem. Res. 2006, 45, 4869-4878.

(14) Austegard, A.; Solbraa, E.; de Koeijer, G.; Mølnvik, M. J. Thermodynamic Models for Calculating Mutual Solubilities in H2O-CO2-CH4 Mixtures. Chem. Eng. Res. Des. 2006, 84 (9 A), 781-794.

(15) Perakis, C.; Voutsas, E.; Magoulas, K.; Tassios, D. Thermodynamic Modeling of the Vapor-Liquid Equilibrium of the water/ethanol/CO2 System. Fluid Phase Equilib. 2006, 
243 (1-2), 142-150.

(16) García, A. V.; Thomsen, K.; Stenby, E. H. Prediction of Mineral Scale Formation in Geothermal and Oilfield Operations Using the Extended UNIQUAC Model. Part II. Carbonate-Scaling Minerals. Geothermics 2006, 35 (3), 239-284.

(17) Spycher, N.; Pruess, K. A Phase-Partitioning Model for CO2-Brine Mixtures at Elevated Temperatures and Pressures: Application to CO2-Enhanced Geothermal Systems. Transp. Porous Media 2010, 82 (1), 173-196.

(18) Hou, S.-X.; Maitland, G. C.; Trusler, J. P. M. Measurement and Modeling of the Phase Behavior of the (Carbon Dioxide+water) Mixture at Temperatures from 298.15K to 448.15K. J. Supercrit. Fluids 2013, 73, 87-96.

(19) Mao, S.; Zhang, D.; Li, Y.; Liu, N. An Improved Model for Calculating CO2 Solubility in Aqueous $\mathrm{NaCl}$ Solutions and the Application to $\mathrm{CO} 2-\mathrm{H} 2 \mathrm{O}-\mathrm{NaCl}$ Fluid Inclusions. Chem. Geol. 2013, 347, 43-58.

(20) Venkatraman, A.; Lake, L. W.; Johns, R. T. Gibbs Free Energy Minimization for Prediction of Solubility of Acid Gases in Water. Ind. Eng. Chem. Res. 2014, 53 (14), 6157-6168.

(21) F. Najmuldeen, G.; Jasim Hadi, G.; Jasim Hadi, A.; Ahmed, I. Gas-Liquid Equilibrium Prediction of Ternary System (CO2-Ethanol-Water) at Moderate Pressures and Different Temperatures Using SRK-EOS. Phys. Chem. 2012, 2 (1), 1-5.

(22) Nakayama, T.; Sagara, H.; Arai, K.; Saito, S. An Equation for the Excess Gibbs Energy of Expandable Liquid Mixtures. J. Chem. Eng. Japan 1988, 21, 509-515. 
(23) Michelsen, M. L.; Mollerup, J. M. Thermodynamic Models: Fundamentals \& Computational Aspects, second.; Tie-Line: Holte, 2007.

(24) Sander, B. Extended UNIFAC/UNIQUAC Models for 1) Gas Solubility Calculations and 2) Electrolyte Solutions, Danmarks Tekniske Højskole, 1984.

(25) Krichevsky, I. R.; Kasarnovsky, J. S. Thermodynamical Calculations of Solubilities of Nitrogen and Hydrogen in Water at High Pressures. J. Am. Chem. Soc. 1935, 57 (11), 2168-2171.

(26) Aspen Technology, Inc, AspenTech http://www.aspentech.com.

(27) Glew, D. N. Aqueous Solubility and the Gas-Hydrates. The Methane-Water System. J. Phys. Chem. 1962, 66, 605-609.

(28) Nocon, G.; Weidlich, U.; Gmehling, J.; Onken, U. Prediction of Gas Solubilities by a Modified UNIFAC Equation. Berichte der Bunsengesellschaft für Phys. Chemie 1983, 87, $17-23$.

(29) Purwanto; Deshpande, R. M.; Chaudhari, R. V.; Delmas, H. Solubility of Hydrogen, Carbon Monoxide, and 1-Octene in Various Solvents and Solvent Mixtures. J. Chem. Eng. Data 1996, 41, 1414-1417.

(30) Prausnitz, J. M.; Shair, F. H. Thermodynamic Correlation of Gas Solubilities. AIChE J. 1961, 7 (4), 682-687.

(31) McKetta Jr., J. J.; Yen, L. C. A Thermodynamic Correlation of Nonpolar Gas Solubilities in Polar, Nonassociated Liquids. AIChE J. 1962, 8 (4), 501-507. 
(32) O’Connell, J. P.; Prausnitz, J. M. Thermodynamics of Gas Solubility in Mixed Solvents. Ind. Eng. Chem. Fundam. 1964, 3 (4), 347-351.

(33) Abrams, D. S.; Prausnitz, J. M. Statistical Thermodynamics of Liquid Mixtures: A New Expression for the Excess Gibbs Energy of Partly or Completely Miscible Systems. AIChE J. 1975, 21 (1), 116-128.

(34) Bondi, A. Van Der Waals Volumes and Radii. J. Phys. Chem. 1964, 68 (3), 441-451.

(35) Peng, D. Y.; Robinson, D. B. A New Two-Constant Equation of State. Ind. Eng. Chem. Fundam. 1976, 15 (1), 59-64.

(36) Hayden, J. G.; O’Connell, J. P. A Generalized Method for Predicting Second Virial Coefficients. Ind. Eng. Chem. Process Des. Dev. 1975, 14 (3), 209-216.

(37) Brigham Young University (BYU), DIADEM Professional DIPPR Information and Data Evaluation Manager http://dechema.de/en/dippr801.html.

(38) Brelvi, S. W.; O’Connell, J. P. Correspondling States Correlations for Liquid Compressibility and Partial Molal Volumes of Gases at Infinite Dilution in Liquids. AIChE J. 1972, 18 (6), 1239-1243.

(39) Chemistry Data Series http://dechema.de/en/CDS.html.

(40) Thomsen, K.; Rasmussen, P.; Gani, R. Correlation and Prediction of Thermal Properties and Phase Behaviour for a Class of Aqueous Electrolyte Systems. Chem. Eng. Sci. 1996, 51, 3675-3683.

(41) Jónasson, A.; Persson, O.; Rasmussen, P.; Soave, S. G. Vapor-Liquid Equilibria of 
Systems Containing Acetic Acid and Gaseous Components. Measurements and Calculations by a Cubic Equation of State. Fluid Phase Equilib. 1998, 152, 67-94.

(42) Maxted, E. B.; Moon, C. H. The Temperature Coefficient of the Solubility of Hydrogen in Organic Solvents. Trans. Faraday Soc. 1936, 32, 769-775.

(43) Just, G. Löslichkeit von Gasen in Organischen Lösungsmitteln. Zeitschrift für Phys. Chemie 1901, 37, 342-367.

(44) Prausnitz, J. M.; Anderson, T.; Grens, E.; Eckert, C.; Hsieh, R.; O’Connell, J. P. Computer Calculations for Multicomponent Vapor-Liquid and Liquid-Liquid Equilibria, first.; Prentice Hall: Englewood Cliffs, New Jersey, 1980.

(45) Batsanov, S. S. Van Der Waals Radii of Hydrogen in Gas-Phase and Condensed Molecules. Struct. Chem. 1999, 10 (6), 395-400.

(46) Sun, T. F.; Ten Seldam, C. A.; Kortbeek, P. J.; Trappeniers, N. J.; Biswas, S. N. Acoustic and Thermodynamic Properties of Ethanol from 273.15 to $333.15 \mathrm{~K}$ and up to $280 \mathrm{MPa}$. Phys. Chem. Liq. 1988, 18, 107-116.

(47) Takiguchi, Y.; Uematsu, M. Densities for Liquid Ethanol in the Temperature Range from $310 \mathrm{~K}$ to $480 \mathrm{~K}$ at Pressures up to $200 \mathrm{MPa}$. J. Chem. Thermodyn. 1996, 28, 7-16.

(48) Vong, W. T.; Tsai, F. N. Densities, Molar Volumes, Thermal Expansion Coefficients, and Isothermal Compressibilities of Organic Acids from $293.15 \mathrm{~K}$ to $323.15 \mathrm{~K}$ and at Pressures up to 25 MPa. J. Chem. Eng. Data 1997, 42, 1116-1120.

(49) Rackett, H. G. Equation of State for Saturated Liquids. J. Chem. Eng. Data 1970, 15, 514517. 
(50) Valtz, A.; Chapoy, A.; Coquelet, C.; Paricaud, P.; Richon, D. Vapour-Liquid Equilibria in the Carbon Dioxide-Water System, Measurement and Modelling from 278.2 to $318.2 \mathrm{~K}$. Fluid Phase Equilib. 2004, 226, 333-344.

(51) King, M. B.; Mubarak, A.; Kim, J. D.; Bott, T. R. The Mutual Solubilities of Water with Supercritical and Liquid Carbon Dioxide. J. Supercrit. Fluids 1992, 5, 296-302.

(52) Nakayama, T.; Sagara, H. High Pressure Liquid-Liquid Equilibria for the System of Water, Ethanol and 1,1-Difluoroethane at 323.2 K. Fluid Phase Equilib. 1987, 38, 109127.

(53) Wiebe, R.; Gaddy, V. L. The Solubility of Carbon Dioxide in Water at Various Temperatures from 12 to $40^{\circ}$ and at Pressures to 500 Atmospheres. Critical Phenomena. $J$. Am. Chem. Soc. 1940, 62 (4), 815-817.

(54) Kiepe, J.; Horstmann, S.; Fischer, K.; Gmehling, J. Experimental Determination and Prediction of Gas Solubility Data for $\mathrm{CO} 2+\mathrm{H} 2 \mathrm{O}$ Mixtures Containing $\mathrm{NaCl}$ or $\mathrm{KCl}$ at Temperatures between 313 and $393 \mathrm{~K}$ and Pressures up to $10 \mathrm{MPa}$. Ind. Eng. Chem. Res. 2002, 41 (17), 4393-4398.

(55) Jung, J.; Knacke, O.; Neuschütz, D. Löslichkeit von Kohlenmonoxid Und Wasserstoff in Wasser Bis $300^{\circ} \mathrm{C}$. Chemie Ing. Tech. 1971, 43, 112-116.

(56) Song, K. Y.; Feneyrou, G.; Fleyfel, F.; Martin, R.; Lievois, J.; Kobayashi, R. Solubility Measurements of Methane and Ethane in Water at and near Hydrate Conditions. Fluid Phase Equilib. 1997, 128, 249-259.

(57) Brunner, E.; Hültenschmidt, W. Fluid Mixtures at High Pressures VIII. Isothermal Phase 
Equilibria in the Binary Mixtures Consisting of (Ethanol+hydrogen or Methane or Ethane). J. Chem. Thermodyn. 1990, 22, 73-84.

(58) Frolich, K.; Tauch, E. J.; Hogan, J. J.; Peer, A. A. Solubilities of Gases in Liquids at High Pressure. Ind. Eng. Chem. 1931, 23, 548-550.

(59) Brelvi, S. W.; O’Connell, J. P. A Generalized Isothermal Equation of State for Dense Liquids. AIChE J. 1975, 21, 171-173. 


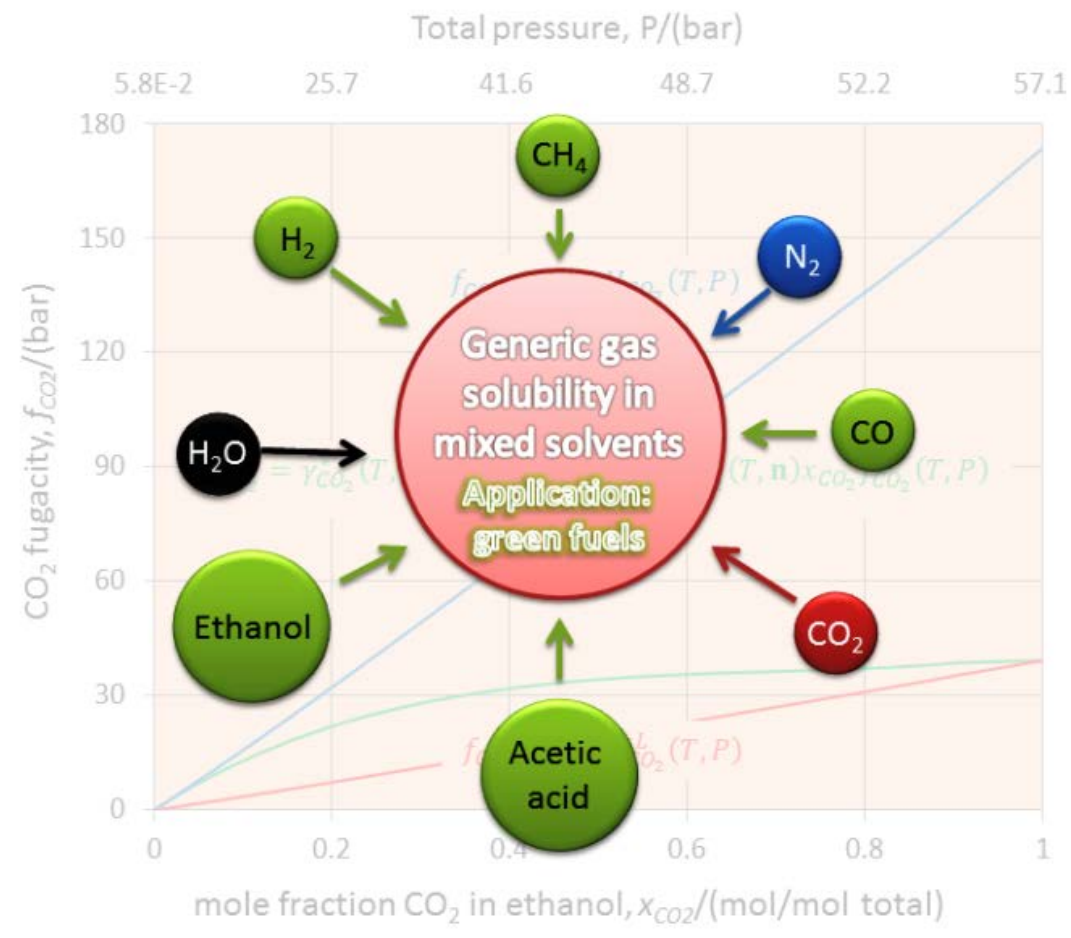

